Atmos. Chem. Phys. Discuss., 8, 16123-16173, 2008 www.atmos-chem-phys-discuss.net/8/16123/2008/ (C) Author(s) 2008. This work is distributed under the Creative Commons Attribution 3.0 License.

This discussion paper is/has been under review for the journal Atmospheric Chemistry and Physics $(A C P)$. Please refer to the corresponding final paper in $A C P$ if available.

\title{
A quasi-Lagrangian coordinate system based on high resolution tracer observations: implementation for the Antarctic polar vortex
}

E. V. Ivanova ${ }^{1}$, C. M. Volk ${ }^{1}$, O. Riediger ${ }^{1}$, H. Klein ${ }^{1}$, N. M. Sitnikov ${ }^{2}$, A. E. Ulanovskii ${ }^{2}$, V. A. Yushkov ${ }^{2}$, F. Ravegnani ${ }^{3}$, T. Möbius ${ }^{1}$, and U. Schmidt ${ }^{1}$

${ }^{1}$ Institut für Atmosphäre und Umwelt, J. W. Goethe Universität Frankfurt, Altenhöferallee 1, 60438 Frankfurt am Main, Germany

${ }^{2}$ Central Aerological Observatory, Pervomayskaya Str. 3, Dolgoprudny, Moscow region, 141700, Russia

${ }^{3}$ Institute of Atmospheric Sciences and Climate, CNR, Via P. Gobetti 101, 40129, Bologna, Italy

Received: 26 May 2008 - Accepted: 28 July 2008 - Published: 25 August 2008

Correspondence to: E. V. Ivanova (ivanova@iau.uni-frankfurt.de)

Published by Copernicus Publications on behalf of the European Geosciences Union.

A quasi-Lagrangian coordinate system based on tracer observations

E. V. Ivanova et al.

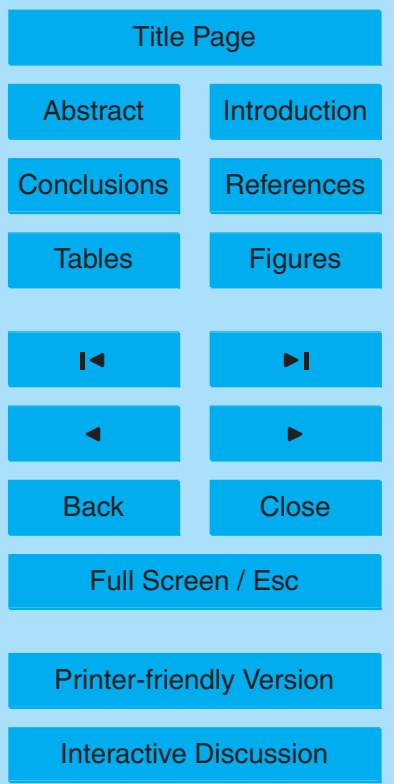




\section{Abstract}

In order to quantitatively analyse the chemical and dynamical evolution of the polar vortex it has proven extremely useful to work with coordinate systems that follow the vortex flow. We propose here a two-dimensional quasi-Lagrangian coordinate system

$5\left\{\chi_{i}, \Delta \chi_{i}\right\}$, based on the mixing ratio of a long-lived stratospheric trace gas $i$, and its systematic use with $i=\mathrm{N}_{2} \mathrm{O}$, in order to describe the structure of a well-developed Antarctic polar vortex. In the coordinate system $\left\{\chi_{i}, \Delta \chi_{i}\right\}$ the mixing ratio $\chi_{i}$ is the vertical coordinate and $\Delta \chi_{i}=\chi_{i}(\Theta)-\chi_{i}^{\text {vort }}(\Theta)$ is the meridional coordinate $\left(\chi_{i}^{\text {vort }}(\Theta)\right.$ being a vertical reference profile in the vortex core). The quasi-Lagrangian coordinates $\left\{\chi_{i}, \Delta \chi_{i}\right\}$ persist for much longer time than standard isentropic coordinates, potential temperature $\Theta$ and equivalent latitude $\varphi_{\mathrm{e}}$, do not require explicit reference to geographic space, and can be derived directly from high-resolution in situ measurements. They are therefore well-suited for studying the evolution of the Antarctic polar vortex throughout the polar winter with respect to the relevant chemical and microphysical processes. By using the introduced coordinate system $\left\{\chi_{\mathrm{N}_{2} \mathrm{O}}, \Delta \chi_{\mathrm{N}_{2} \mathrm{O}}\right\}$ we analyze the well-developed Antarctic vortex investigated during the APE-GAIA (Airborne Polar Experiment - Geophysica Aircraft in Antarctica - 1999) campaign (Carli et al., 2000). A criterion, which uses the local in-situ measurements of $\chi_{i}=\chi_{i}(\Theta)$ and attributes the inner vortex edge to a rapid change ( $\delta$-step) in the meridional profile of the mixing ratio $\chi_{i}$, is developed to determine the (Antarctic) inner vortex edge. In turn, we suggest that the outer vortex edge of a well-developed Antarctic vortex can be attributed to the position of a local minimum of the $\chi_{\mathrm{H}_{2} \mathrm{O}}$ gradient in the polar vortex area. For a well-developed Antarctic vortex, the $\Delta \chi_{\mathrm{N}_{2} \mathrm{O}}$-parametrization of tracer-tracer relationships allows to distinguish the tracer inter-relationships in the vortex core, vortex boundary region and surf zone and to examine their meridional variation throughout these regions. This is illustrated by analyzing the tracer-tracer relationships $\chi_{i}: \chi_{\mathrm{N}_{2} \mathrm{O}}$ obtained from the in-situ data of the APE-GAIA campaign for $i=$ CFC-11, CFC-12, $\mathrm{H}-1211$ and $\mathrm{SF}_{6}$. A number of solitary anomalous points in the CFC-11: $\mathrm{N}_{2} \mathrm{O}$ correlation, observed in the Antarctic vortex

A quasi-Lagrangian coordinate system based on tracer observations

E. V. Ivanova et al.

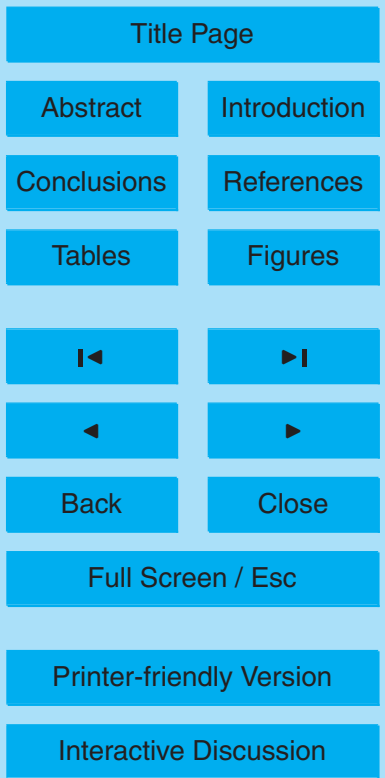




\section{Introduction}

According to the current understanding (Tuck et al., 1995; Haynes and Shuckburgh, 2000b; Lee et al., 2001; WMO, 2003; Tilmes et al., 2006; WMO, 2007), the structure of the well-developed Antarctic polar vortex (from May through October) can be described in terms of a quasi-isolated vortex core which is separated from the middle latitude surf zone by a relatively wide (about $10^{\circ}$ latitude) vortex boundary region (see Fig. 1). The vortex core can be interpreted as a quasi-isolated containment vessel where long-lived gases are well-mixed (Randel, 1993; WMO, 2003) and exhibits, in the absence of large chemical changes, compact tracer-tracer relationships (Michelsen et al., 1998; Müller et al., 2005; Plumb, 2007). The external surf zone stratosphere is also well-mixed (Haynes and Shuckburgh, 2000a; Lee et al., 2001). In contrast with these two stratospheric areas, the vortex boundary region is characterized by weak mixing. Furthermore, the strong circumpolar winds, i.e. the polar night jet, and the strong merid15 ional gradients of the potential vorticity $P$ (Ertel, 1942) in the vortex boundary region give rise to a transport barrier and strongly suppress the penetration of air from the surf zone into the vortex core and vice versa (e.g., Schoeberl and Hartmann, 1991; Labitzke, 1999).

A well-distinguishable Antarctic vortex boundary region, which was observed (e.g., 20 Tuck et al., 1995) and simulated (Lee et al., 2001), persists normally for several months, until the polar vortex breakdown. The sudden warming in the year 2002 is the only known splitting of the Antarctic vortex since the first observations in the 1950s (Roscoe et al., 2005). When the Antarctic vortex is well-developed, the area of the boundary region is comparable with the size of the polar vortex core. After mid-October the boundary region starts to shrink in size, so that by the end of November the Antarctic vortex boundary region and the transport barrier associated with it are already considerably reduced (Haynes and Shuckburgh, 2000a; Lee et al., 2001).

\section{A quasi-Lagrangian coordinate system based on tracer observations}

E. V. Ivanova et al.

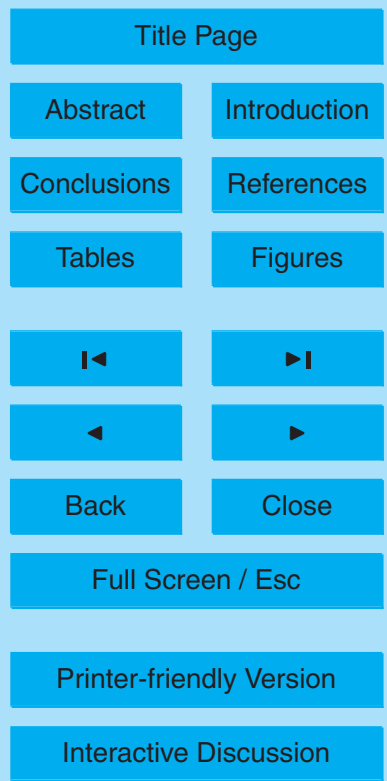


While quantities like potential vorticity $P$ and equivalent latitude $\varphi_{\mathrm{e}}$ (Butchart and Remsberg, 1986) are readily available and extremely helpful in characterizing the gross structure of the polar vortex from a dynamical point of view, their use in the investigation of chemical processes has two major drawbacks. Firstly $P$ is a derived quantity 5 available only at relatively coarse resolution, such that small-scale features as vortex filaments relevant for chemistry are often not resolved or not exactly reproduced in space and time. Secondly, $P$ is only conserved for about 10 days in the polar lower stratosphere and is thus not suitable in describing the chemical evolution of air parcels over longer time scales. In contrast, there exist long-lived tracers that can be mea10 sured directly at higher resolution and that are conserved over time scales exceeding a polar winter. It has thus become popular to use long-lived tracers in quantifying the chemical evolution of the polar vortex, in particular with respect to ozone depletion and denitrification (e.g., Proffitt et al., 1989b; Fahey et al., 1990; Müller et al., 2005). Most common has been the use of $\mathrm{N}_{2} \mathrm{O}$ which is chemically inert in the troposphere and 15 lower stratosphere.

$\mathrm{N}_{2} \mathrm{O}$, as other trace gases, follows the Brewer-Dobson circulation: it enters the lower stratosphere from the tropical tropopause at potential temperature $\Theta \simeq 380 \mathrm{~K}$ with $\chi_{\mathrm{N}_{2} \mathrm{O}} \simeq 315 \mathrm{ppb}$, propagates in the stratosphere towards the poles, experiences the partial destruction in the upper stratosphere, descends at high latitudes, and finally returns back to the troposphere. The horizontal gradient of $\chi_{\mathrm{N}_{2} \mathrm{O}}$ is much smaller than the vertical one, $\left|\nabla_{x, y} \chi_{\mathrm{N}_{2} \mathrm{O}}\right| \ll\left|\nabla_{z} \chi_{\mathrm{N}_{2} \mathrm{O}}\right|$. The largest horizontal gradients occur in the relatively narrow polar vortex boundary region, which is located between the outer surf zone and inner vortex core. In the Northern Hemisphere the maximum value evaluated along the isentropic surfaces can be as high as $\left|\nabla \chi_{\mathrm{N}_{2} \mathrm{O}}^{\mathrm{max}}\right| \simeq 8 \mathrm{ppb} / \mathrm{km}(\Theta=465 \mathrm{~K}$ surface $)$, 25 while for the Antarctic vortex boundary $\mid \nabla \chi_{\mathrm{N}_{2} \mathrm{O}}^{\max } \simeq 2.5 \mathrm{ppb} / \mathrm{km}(\Theta=495 \mathrm{~K}$ surface) (Strahan et al., 1999). In the presence of a well-developed polar vortex (winter season), the mixing ratio $\chi_{\mathrm{N}_{2} \mathrm{O}}$ at a given $\Theta$ is nearly constant inside the vortex core and increases slowly towards the equator in the surf zone at a given isentropic surface. The variability of $\chi_{\mathrm{N}_{2} \mathrm{O}} \mathrm{O}_{\Theta=\text { const }}$ in the Arctic vortex core is $\simeq 6 \mathrm{ppb}$ (Greenblatt et al., 2002).

A quasi-Lagrangian coordinate system based on tracer observations

E. V. Ivanova et al.

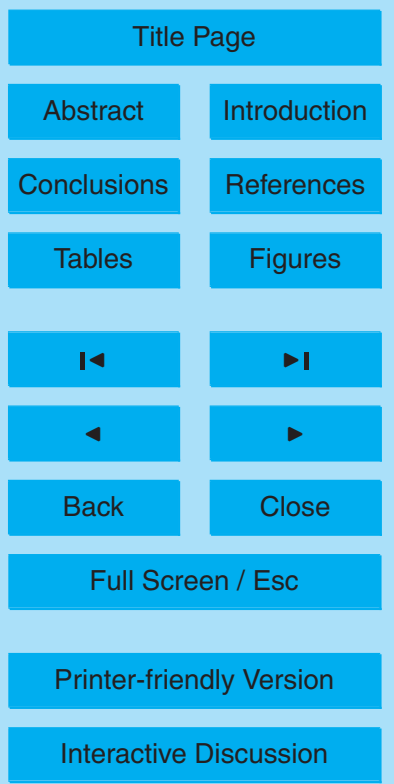


In Sect. 3 of this paper, we propose a two-dimensional quasi-Lagrangian coordinate system $\left\{\chi_{i}, \Delta \chi_{i}\right\}$ based on a long-lived stratospheric trace gas $i$ to describe the evolution of ozone, $\mathrm{H}_{2} \mathrm{O}$ and other trace gases in the polar stratosphere, instead of the standard altitude-latitude coordinates, or the potential temperature $\Theta$ and equivalent 5 latitude $\varphi_{\mathrm{e}}$. The quasi-Lagrangian coordinates $\left\{\chi_{i}, \Delta \chi_{i}\right\}$, which are associated with an air-parcel moving in the stratosphere, are much more long-lived than the isentropic $\left\{\Theta, \varphi_{\mathrm{e}}\right\}$. In the coordinate system $\left\{\chi_{i}, \Delta \chi_{i}\right\}$, which refers to a well-developed polar vortex, the mixing ratio $\chi_{i}$ is the vertical coordinate and $\Delta \chi_{i}=\chi_{i}-\chi_{i}^{\text {vort }}$, the distance from the vortex core on an isentrope measured in terms of mixing ratio, is the merid10 ional coordinate. The quasi-Lagrangian coordinate $\Delta \chi_{i}$ requires the use of the vertical profile $\chi_{i}^{\text {vort }}(\Theta)$ which has to be measured in the vortex core, when the polar vortex is already well-developed. Furthermore, the quasi-Lagrangian coordinates $\left\{\chi_{i}, \Delta \chi_{i}\right\}$ do not require explicit reference to geographic space. This makes the $\left\{\chi_{i}, \Delta \chi_{i}\right\}$ coordinate system very favourable for the evaluation of polar ozone loss. We will refer to 15 this description of the polar stratosphere using the $\left\{\chi_{i}, \Delta \chi_{i}\right\}$ coordinate system as the $\Delta \chi$-method. In order to demonstrate and validate the concept and its application we use in situ data obtained in the Antarctic vortex during the APE-GAIA aircraft campaign (Carli et al., 2000). The observations are briefly discussed in Sect. 2. The method is, however, not restricted to the Antarctic vortex, but can be implemented in the Arctic polar stratosphere as well.

The properties of $\mathrm{N}_{2} \mathrm{O}$ described above make this trace gas very suitable for the quasi-Lagrangian coordinate system $\left\{\chi_{i}, \Delta \chi_{i}\right\}\left(i=\mathrm{N}_{2} \mathrm{O}\right)$. In Sect. 4 of this paper, the tracer-tracer relationships $\chi_{i}: \chi_{\mathrm{N}_{2} \mathrm{O}}$ are analyzed for $i=\mathrm{CFC}-11, \mathrm{CFC}-12, \mathrm{H}-1211$ and $\mathrm{SF}_{6}$ by using $\Delta \chi_{\mathrm{N}_{2} \mathrm{O}}$ bins $\left(\Delta \chi_{\mathrm{N}_{2} \mathrm{O}}\right.$ parametrization; $\Delta \chi_{\mathrm{N}_{2} \mathrm{O}}$ can also be interpreted as a meridional coordinate). A particular emphasis is made on the tracer-tracer correlations in the Antarctic polar vortex core, and their character and time evolution are attributed to the compactization and linearization which arise and develop in the Antarctic vortex core. In Sect. 5 we examine solitary anomalous points in the tracer-tracer correlations, observed in the well-developed Antarctic vortex core during the APE-GAIA and ASHOE

A quasi-Lagrangian coordinate system based on tracer observations

E. V. Ivanova et al.

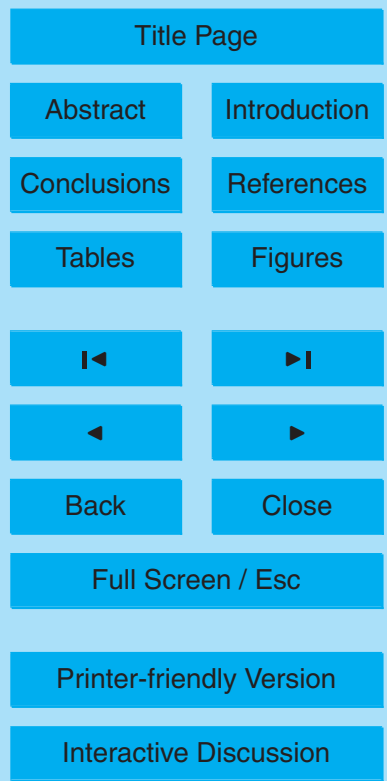

\section{7}


(Airborne Southern Hemisphere Ozone Experiment - 1994) campaigns. Finally, in Sect. 6 the water vapour in the lower stratosphere is discussed, and the developed $\Delta \chi$-method is applied to lower-stratospheric $\mathrm{H}_{2} \mathrm{O}$ in the Antarctic vortex area. In this case both edges, inner and outer, of the well-developed Antarctic vortex can reliably 5 be found completely determining the polar vortex boundary region.

\section{Campaigns and instrumentation}

In order to demonstrate, validate, and apply the concepts proposed in this study we use airborne in situ tracer data acquired on board the high altitude research aircraft M55 Geophysica during the Airborne Polar Experiment - Geophysica Aircraft in Antarctica (APE-GAIA). The APE-GAIA campaign was based in Ushuaia, Argentina $\left\{55^{\circ} \mathrm{S}, 68^{\circ} \mathrm{W}\right\}$ in the austral spring 1999, from 15th September to 15th October. The aims of the campaign included the investigation of the chemical composition of the Antarctic polar vortex, of mixing and transport processes in this area, and of the dynamics of the re-activation of the stratospheric chlorine/bromine reservoir. A more detailed descrip15 tion of the APE-GAIA campaign is given in Carli et al. (2000). The M55 Geophysica, equipped with instruments developed and operated by various European institutes, performed five research flights (on 21 and 23 September, and on 2, 8 and 12 October) from Ushuaia towards and into the Antarctic vortex up to $70^{\circ} \mathrm{S}$ latitude at altitudes from $14 \mathrm{~km}$ up to nearly $21 \mathrm{~km}$. During three of these flights (on 21 and 23 September, and on 12 October) the aircraft well penetrated into the Antarctic polar vortex core. In addition, in one more research flight (on 2 October) the aircraft crossed the inner vortex edge and briefly touched the vortex core.

The High Altitude Gas Analyzer (HAGAR), a two-channel gas chromatograph using electron capture detection (GC/ECD) in combination with a carbon dioxide infrared absorption analyzer, was developed and operated by the University of Frankfurt (Strunk, 1999; Riediger, 2000). During APE-GAIA the first chromatographic channel was configured to measure $\mathrm{SF}_{6}$ every $45 \mathrm{~s}$, while in the second chromatographic channel

A quasi-Lagrangian coordinate system based on tracer observations

E. V. Ivanova et al.

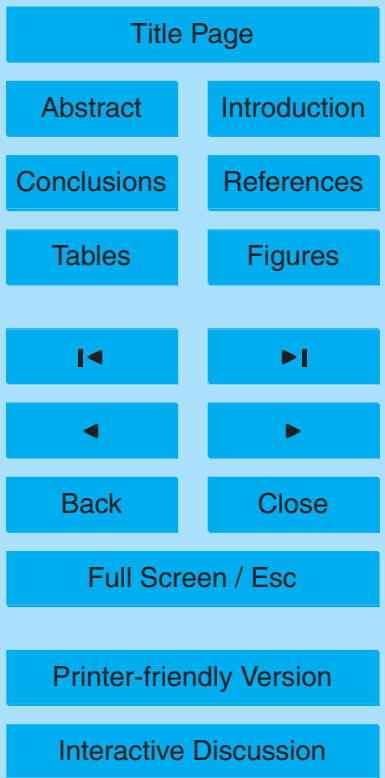


the following trace gases were detected every $90 \mathrm{~s}: \mathrm{N}_{2} \mathrm{O}, \mathrm{CFC}-12\left(\mathrm{CF}_{2} \mathrm{Cl}_{2}\right), \mathrm{H}-1211$ $\left(\mathrm{CBrClF}_{2}\right)$ and $\mathrm{CFC}-11\left(\mathrm{CFCl}_{3}\right)$. The $\mathrm{CO}_{2}$ sensor of HAGAR, which is a modified commercial IR absorption gas analyzer (LI-COR 6251), operates in parallel with the chromatographic channels and measures carbon dioxide every $10 \mathrm{~s}$. Measurements of 5 the trace gases with HAGAR, the in-flight two-standard calibration, and the processing schemes of HAGAR's chromatograms are discussed in detail in Riediger (2000) and Ivanova (2007). The vertical distribution of the mixing ratio $\chi_{\mathrm{N}_{2} \mathrm{O}}(\Theta)$ as recorded with HAGAR in the Southern high latitude stratosphere during the APE-GAIA campaign is plotted in Fig. 2. The measurements reach a potential temperature of $500 \mathrm{~K}$ 10 in the vortex edge region, but only of $460 \mathrm{~K}$ in the vortex core (highest latitudes). In order to create an $\mathrm{N}_{2} \mathrm{O}$ profile representative of the vortex core up to $500 \mathrm{~K}$ we extrapolate the HAGAR $\mathrm{N}_{2} \mathrm{O}$ data using satellite data from October 2002 measured by the Improved Limb Atmospheric Spectrometer (ILAS-II) on board the ADEOS-II Satellite (e.g., Sasano et al., 1999; Tilmes et al., 2006).

15 In the following sections we also use ozone and water vapour measurements made on board the Geophysica aircraft during APE-GAIA. Ozone was measured every $0.5 \mathrm{~s}$ by the Fast Ozone Analyser (FOZAN), an instrument based on the chemiluminescence technique and operated by CAO (Russia) and CNR (Italy) (Yushkov et al., 1999). Water vapour was measured every second by the Fluorescent Airborne Stratospheric 20 Hygrometer (FLASH), an instrument based on the Lyman-alpha technique and also operated by CAO (Sitnikov et al., 2007).

\section{Method: $\Delta \chi$ as a quasi-Lagrangian meridional coordinate}

An accurate quantification of chemical changes, e.g. ozone losses, based on observations in the vortex area usually requires that the vortex boundaries are reliably found

25 (e.g., Müller et al., 2005). However, the exact determination of the inner and outer vortex edges is a challenging task. The geographical latitude and the altitude are not proper coordinates for describing polar vortices because the polar vortex continuously

A quasi-Lagrangian coordinate system based on tracer observations

E. V. Ivanova et al.

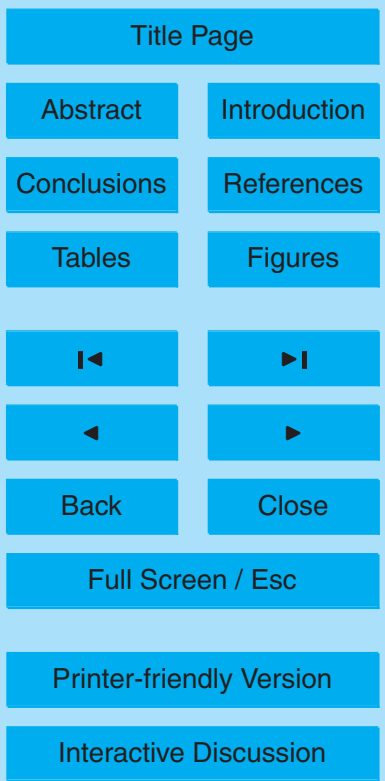


moves and changes its shape. In order to locate data points with respect to the vortex core, early studies used quantities like wind speed maximum (e.g., Tuck et al., 1995) or maximum gradient potential vorticity $P$ (e.g., Schoeberl and Hartmann, 1991) in order to find the polar vortex boundary. Nowadays one of the frequently used approaches is 5 to apply the Nash criterion (Nash et al., 1996; Coy et al., 1997) that attributes the polar vortex edge to the maximum of the gradient $\partial P\left(\Theta, \varphi_{\mathrm{e}}\right) / \partial \varphi_{\mathrm{e}}$, i.e. to $\varphi_{\mathrm{e}}=\varphi_{\mathrm{e}}^{\mathrm{v} \text {.e. }}$ defined by the condition:

$\left.\frac{\partial^{2} P}{\partial \varphi_{\mathrm{e}}^{2}}\right|_{\varphi_{\mathrm{e}}=\varphi_{\mathrm{e}}^{\text {v.e. }}}=0$,

provided that there is a closely located maximum of the average wind velocity tangent 10 to the $P$-isopleth contour (Strahan et al., 1989). In this case, the inner and outer nearby inflection points, $\varphi_{\mathrm{e}}^{\text {i.v.e. }}$ and $\varphi_{\mathrm{e}}^{\text {o.v.e. }}>\varphi_{\mathrm{e}}^{\text {i.v.e. }}$, defined by the condition

$\left.\frac{\partial^{3} P}{\partial \varphi_{\mathrm{e}}^{3}}\right|_{\varphi_{\mathrm{e}}=\varphi_{\mathrm{e}}^{\text {i.v.e. }}}=\left.\frac{\partial^{3} P}{\partial \varphi_{\mathrm{e}}^{3}}\right|_{\varphi_{\mathrm{e}}=\varphi_{\mathrm{e}}^{\text {o.v.e. }}}=0$

refer to the inner and outer vortex edges, respectively, i.e. determine the vortex boundary region.

The Nash criterion is based on a meteorological analysis of the global stratospheric dynamics and well suited for application to satellite data on the gross structure of the polar stratosphere. However, this method is not very accurate in finding the inner and outer vortex edges (Greenblatt et al., 2002; Proffitt et al., 2003). Indeed, Eq. (2) deals with the third derivative of the potential vorticity $P$ and therefore cannot be accurately evaluated. On the other hand, the meridional gradient (i.e., the gradient along an isentropic surface) of the mixing ratio $\left.\chi_{i}\right|_{\Theta=c o n s t}$ of trace gases reaches maximum values in the vortex boundary region (Proffitt et al., 1989a,b,c; Schoeberl and Hartmann, 1991; Schoeberl et al., 1992; Proffitt et al., 1992; Waugh et al., 1997; Gao et al., 2002; Müller et al., 2005). At the same time, $\chi_{i}$ is nearly constant on $\Theta$-surfaces within the vortex core and in the surf zone (see Fig. 3 ; in the surf zone $\chi_{i}$ slightly increases towards the

A quasi-Lagrangian coordinate system based on tracer observations

E. V. Ivanova et al.

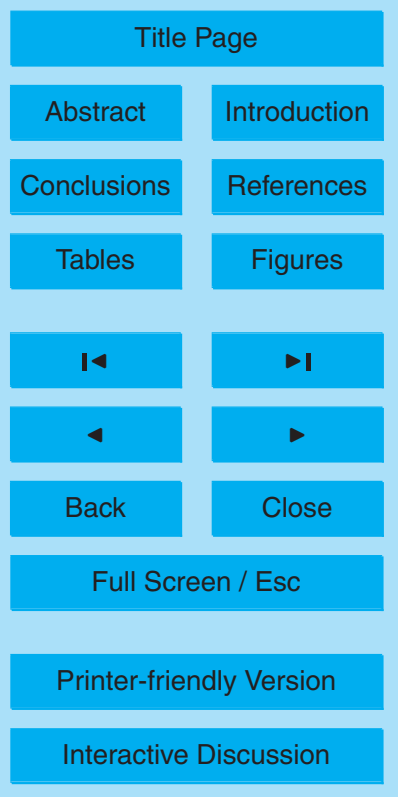


equator e.g., Plumb and Ko, 1992; Plumb, 2002). This gives a hint to use the $\left.\chi_{i}\right|_{\Theta=c o n s t}$ meridional profiles of a trace gas $i$ in order to define more accurately the vortex boundary region. Such a definition, which is based on observation of the local stratospheric dynamics, is potentially suitable for a more detailed resolution of the fine structure of 5 the vortex boundary area, including vortex filaments with "steps" in the mixing ratio profile. The steps in the mixing ratio distribution of a tracer along the isentropic surface at the location of stratospheric transport barriers are widely described in the literature cited above. A mechanism of their appearance is discussed in Haynes (1999).

Greenblatt et al. (2002) propose to determine the inner edge of the Arctic polar vor10 tex by a certain difference in $\mathrm{N}_{2} \mathrm{O}$ mixing ratio $\left(\Delta \mathrm{N}_{2} \mathrm{O}=20 \mathrm{ppb}\right)$ from a profile $\mathrm{N}_{2} \mathrm{O}(\Theta)$ measured in-situ in the vortex core. In the present study we extend on this approach and propose to use a tracer distance from the vortex core $\Delta \chi_{i}(\Theta)=\chi_{i}(\Theta)-\chi_{i}^{\text {vort }}(\Theta)$ as a meridional coordinate with the aim of quantifying dynamical and chemical processes in the vortex boundary region and vortex core. This approach can be realized in the 15 following steps:

(i) Choose a trace gas $i$ with a well-measured (reference) mixing ratio profile $\chi_{i}^{\text {vort }}(\Theta)$ in the vortex core. The reference mixing ratio can either be directly measured during an aircraft flight or balloon launch within the vortex core or inferred from several aircraft flights, separated by not more than few days, across the vortex core.

(ii) By using airborne measurements taken during a flight into (and back out of) the polar vortex, identify a $\delta$-step (or several of them) in the mixing ratio distribution $\left.\chi_{i}\right|_{\Theta=\text { const }}$ (see Fig. 3). The inner vortex edge is attributed to the $\delta$-step, where the horizontal gradient $\left|\nabla \chi_{i}\right|$ has a maximum value. Observations obtained poleward of such $\delta$-steps belong to the vortex core and have to be used for finding the $\chi_{i}^{\text {vort }}(\Theta)$ profile.

(iii) Introduce a quasi-Lagrangian relative coordinate $\Delta \chi_{i}$ as $\Delta \chi_{i}(\Theta)=\chi_{i}(\Theta)-\chi_{i}^{\text {vort }}(\Theta)$.

The measurement points with $\left.\Delta \chi_{i}\right|_{\Theta=\text { const }} \leq\left.\delta_{\chi_{i}}\right|_{\Theta=\text { const }}\left(\left.\Delta \chi_{i}\right|_{\Theta=\text { const }}>\left.\delta_{\chi_{i}}\right|_{\Theta=\text { const }}\right)$ are classified as belonging to the vortex core (to the vortex boundary region or to the surf zone).

A quasi-Lagrangian coordinate system based on tracer observations

E. V. Ivanova et al.

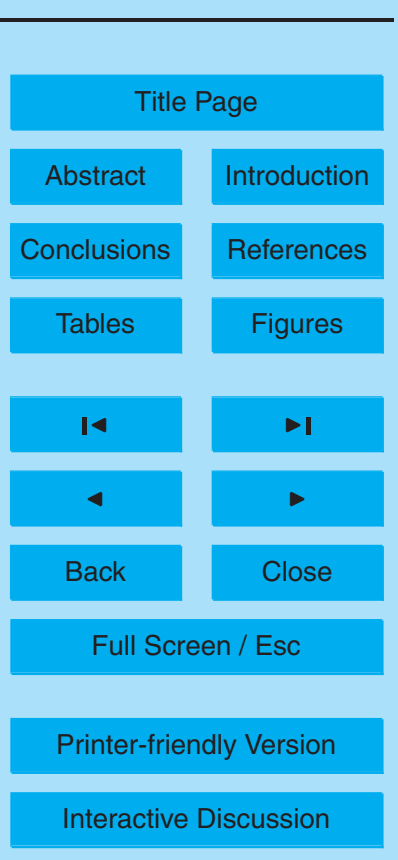


The proposed $\delta \chi$-criterion for determining inner vortex edge can only be applied to a well-developed polar vortex, when the $\delta$-steps in the $\left.\chi_{i}\right|_{\Theta=c o n s t}$ meridional profiles are clearly seen. For the majority of trace gases, a similar approach cannot be used for finding the outer vortex edge, due to the gradual change of the mixing ratios with no 5 observable $\delta$-steps in this area. However, the $\mathrm{H}_{2} \mathrm{O}$ mixing ratio allows to determine not only the inner, but also the outer vortex edge, as detailed in the last part of this paper. The proposed quantitative definition of the inner vortex edge is illustrated below by analyzing $\mathrm{N}_{2} \mathrm{O}$ observations for a set of research flights during the APE-GAIA campaign.

10 In order to create the $\chi_{\mathrm{N}_{2} \mathrm{O}}^{\mathrm{vor}}(\Theta)$ reference function for the Antarctic vortex 1999, four research flights into the Antarctic vortex were selected: On 21 and 23 September, and on 2 and 12 October (see Fig. 4, where the vortex core segments of the $\chi_{\mathrm{N}_{2} \mathrm{O}}$ distribution are marked by the blue colour). According to Fig. 4c, only a small part of the research flight on 2 October was inside the Antarctic vortex core. The $\delta$-steps in 15 the $\chi_{\mathrm{N}_{2} \mathrm{O}}$-distribution can clearly be identified (the start and terminal points of the blue segments in Figs. $4 \mathrm{a}-\mathrm{d}$. The very narrow $\delta$-step areas correspond to the points where the flight trajectory crosses the inner vortex edge. It would be preferable to measure the reference profile $\chi_{\mathrm{N}_{2} \mathrm{O}}^{\mathrm{vort}}(\Theta)$ in a special aircraft flight or balloon launch deep inside the Antarctic vortex core. However, such data are not available for the APE-GAIA campaign 20 So that the reference function was inferred by combining the vortex core data collected in the four flights specified above.

As $\delta_{\chi_{\mathrm{N}_{2} \mathrm{O}}}$, we use here $20 \mathrm{ppb}$, the same value proposed by Greenblatt et al. (2002) as maximum difference $\Delta \mathrm{N}_{2} \mathrm{O}$ from the reference profile in the Arctic vortex. This value roughly corresponds to the smallest of the $\chi_{\mathrm{N}_{2} \mathrm{O}}$-steps identified in Fig. $4 \mathrm{~b}$ as edge of 25 the vortex core. Figure 5 shows that this value indeed provides a reasonable separation of data located poleward (blue) and equatorward (red) of the $\delta$-steps observed in the Antarctic vortex region during APE-GAIA. The figure shows the $\chi_{\mathrm{N}_{2} \mathrm{O}}(\Theta)$ data points measured in all five research flights of the APE-GAIA campaign Fig. 5 . The behaviour of the mixing ratio $\chi_{\mathrm{N}_{2} \mathrm{O}}$ through four of these research flights is detailed in Fig. 4. The 16132

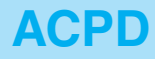

8, 16123-16173, 2008

\section{A quasi-Lagrangian coordinate system based on tracer observations}

E. V. Ivanova et al.

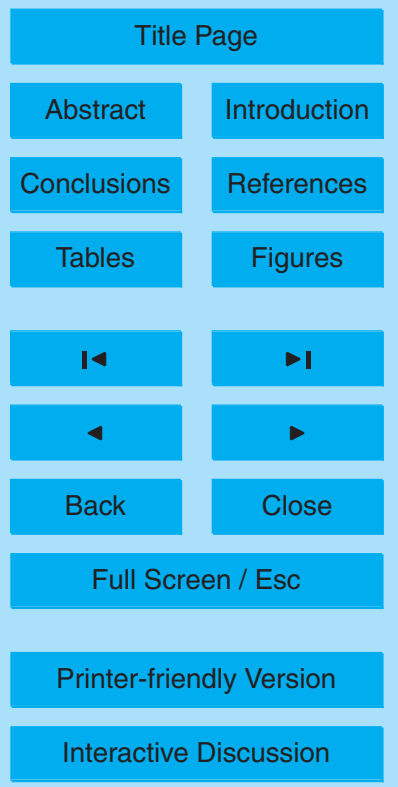


fifth research flight did not cross the vortex inner edge. In Fig. 5, the vortex reference profile $\chi_{\mathrm{N}_{2} \mathrm{O}}^{\mathrm{vort}}(\Theta)$ calculated by least-square fitting of the data recorded in the vortex core is shown by the blue line, and the inner vortex edge determined with $\delta_{\chi_{\mathrm{N}_{2} \mathrm{O}}}=20 \mathrm{ppb}$ is shown by the blue dashed line.

The $\delta \chi$-criterion is compared with the Nash criterion, Eq. (2), in Fig. 6 for the research flight on 23 September of the APE-GAIA campaign. The values of $\varphi_{\mathrm{e}}$ and the vortex edge location, evaluated according to the Nash criterion, are obtained from ECMWF (European Centre for Medium-Range Weather Forecasts) data. The difference between the positions of the inner vortex edge calculated with two criteria is 0 about $230 \mathrm{~km}$ (see the vertical solid and dashed lines in Fig. 6). A similar difference of about $400 \mathrm{~km}$ is also found in Greenblatt et al. (2002) for the Arctic vortex. At the same time the width of the inner vortex boundary, where the maximum horizontal gradients of $\chi_{\mathrm{N}_{2} \mathrm{O}}$ occur, is much less than the difference in the positions evaluated with the Nash and $\delta \chi$ criteria. For example, for the left-hand side inner vortex edge shown in Fig. $6 \mathrm{a}$, 15 the width of the boundary is about $36 \mathrm{~km}$ and $\left|\nabla \chi_{\mathrm{N}_{2} \mathrm{O}}^{\max }\right| \simeq 0.8 \mathrm{ppb} / \mathrm{km}$. The positions of the inner polar vortex edge evaluated with the $\delta \chi$ and Nash criteria are compared in Table 1 for four research flights of the APA-GAIA campaign. Thus the (global) Nash criterion cannot provide us with a high-resolution estimate of the inner vortex edge. The latter can accurately be found by using the $\delta \chi$-criterion based on local characteristics 20 of the trace gases.

Because of the dynamic properties, a tracer-tracer correlation is different for the vortex core, vortex boundary region, and surf zone. This can be seen by analyzing the tracer-tracer correlation functions with the use of the equivalent latitude $\varphi_{\mathrm{e}}$, which, in turn, is ascribed to one of the main areas (vortex core, boundary region, and surf zone) by applying the Nash criterion, Eqs. (1-2).

Figure 7 shows the Antarctic vortex boundaries evaluated with the Nash criterion for the research flights of the APE-GAIA campaign. In Fig. 7, six non-equidistant $\varphi_{\mathrm{e}}$-bins $(\mathrm{I}-\mathrm{VI})$ are indicated. Bin I refers to the vortex core without any air masses belonging to the vortex boundary region. Bin II can also be described mainly as the vortex core.

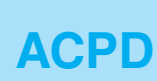

8, 16123-16173, 2008

\section{A quasi-Lagrangian coordinate system based on tracer observations}

E. V. Ivanova et al.

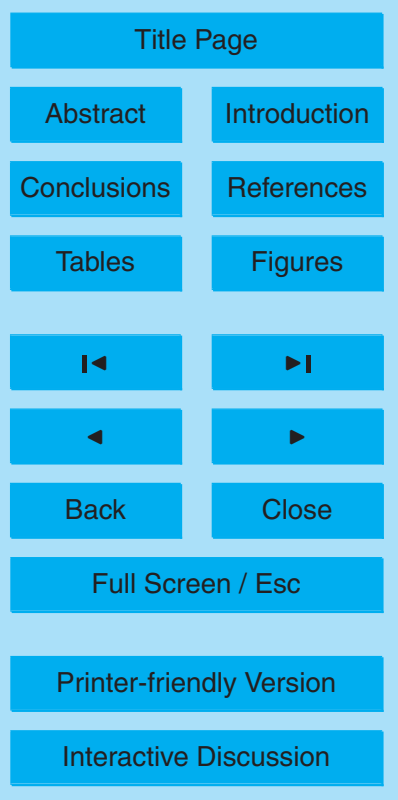


Bin III can be characterized as the inner vortex edge area with practically no intrusion of air from the main vortex boundary area (Note, however, the blue curve that starts to penetrate into the bin at $\Theta \gtrsim 480 \mathrm{~K}$ ). Bin IV refers to air from the main vortex boundary area, with no intrusions of air from the inner and outer edges, at least for $\Theta \gtrsim 400 \mathrm{~K}$. 5 Bin $V$ contains air from the outer edge area of the vortex boundary region. Starting from bin $\mathrm{VI}$, the stratospheric air masses are clean from vortex air. Thus, bins III-V characterize the Antarctic vortex boundary region, $53^{\circ} S \lesssim \varphi_{\mathrm{e}}^{\mathrm{vbr}} \lesssim 65^{\circ} \mathrm{S}$, which existed during the APE-GAIA campaign. The $\mathrm{O}_{3}: \mathrm{N}_{2} \mathrm{O}$ correlation data points binned in terms of the equivalent latitude coordinate are plotted in Fig. $8 \mathrm{a}$. The bin labels, I-VI, near 10 the solid lines in Fig. 8a indicate the corresponding $\mathrm{O}_{3}: \mathrm{N}_{2} \mathrm{O}$ relationship.

The quasi-Lagrangian meridional, $\Delta \chi_{\mathrm{N}_{2} \mathrm{O}}$, and equivalent latitude, $\varphi_{\mathrm{e}}$, coordinates are compared in Fig. 8 by analyzing the $\mathrm{O}_{3}: \mathrm{N}_{2} \mathrm{O}$ correlation function evaluated from the data of the APE-GAIA campaign. In Fig. $8 \mathrm{~b}$, the correlation is equidistantly $\Delta \chi_{\mathrm{N}_{2} \mathrm{O}^{-}}$ binned with $\left[\Delta \chi_{\mathrm{N}_{2} \mathrm{O}}\right]_{\text {bin }}=20 \mathrm{ppb}$ from $\chi_{\mathrm{N}_{2} \mathrm{O}}^{\mathrm{vort}}(\Theta)$. For this plot, the quasi-Lagrangian co15 ordinate $\Delta \chi_{\mathrm{N}_{2} \mathrm{O}}$ varies from $-32 \mathrm{ppb}$ to $145 \mathrm{ppb}$. According to the $\delta \chi$-criterion with $\delta_{\chi_{\mathrm{N}_{2} \mathrm{O}}}=20 \mathrm{ppb}$, the area within the inner vortex edge is given by $\Delta \chi_{\mathrm{N}_{2} \mathrm{O}} \leq 20 \mathrm{ppb}$ (see the dark blue crosses and light blue circles in Fig. 8b).

Figure 8 shows that the $\mathrm{O}_{3}: \mathrm{N}_{2} \mathrm{O}$ distribution is rather compact in the vortex core and surf zone areas (note that in these regions the fitting lines for the equidistant $\Delta \chi_{\mathrm{N}_{2} \mathrm{O}}$ 20 bins nearly coincide) and is not compact in the vortex boundary region. The positive correlation of the $\mathrm{O}_{3}$ and $\mathrm{N}_{2} \mathrm{O}$ mixing ratios in the vortex core is also clearly observed (see in Fig. 8 the dark blue and light blue straight fitting lines with a positive slope) (Strahan et al., 1989). However, the main message of Fig. 8 is that the quasi-Lagrangian $\Delta \chi_{\mathrm{N}_{2} \mathrm{O}}$ coordinate is more suitable for an analysis of the in situ experimental data than the equivalent latitude coordinate. Indeed, the data points can be binned much more reliably, and with much less scatter of the $\mathrm{O}_{3}: \mathrm{N}_{2} \mathrm{O}$ correlation, in terms of the $\Delta \chi_{\mathrm{N}_{2} \mathrm{O}}$ coordinate than in terms of the $\varphi_{\mathrm{e}}$ coordinate (see Fig. 8a against Fig. 8b). Furthermore, the inner vortex edge is much better defined by the $\delta \chi$-criterion (local $\Delta \chi_{\mathrm{N}_{2} \mathrm{O}}$ coordinate) than by the Nash criterion (global $\varphi_{\mathrm{e}}$ coordinate).

A quasi-Lagrangian coordinate system based on tracer observations

E. V. Ivanova et al.

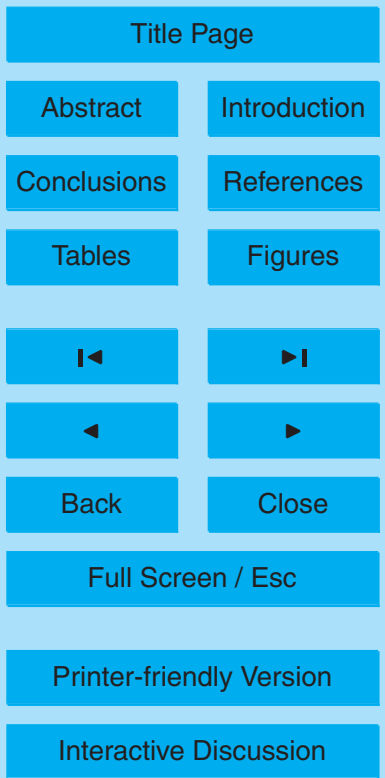

Interactive Discussion 
The use of the $\Delta \chi_{\mathrm{N}_{2} \mathrm{O}}$ coordinate in order to identify a filament which was observed in the research flight on 8 Ocober 1999 of the APE-GAIA campaign is illustrated in Fig. 9. In this case the flight trajectory did not cross the vortex boundary region. The vortex filament was initially found as a region with a rapid local decrease of the modified po5 tential vorticity, from $\Pi_{\varepsilon} \simeq-10 \mathrm{PVU}$ to $\Pi_{\varepsilon}^{\text {fil }} \simeq-16 \mathrm{PVU}$ (Riediger, 2000) (see the region marked by the vertical dashed lines in Fig. 9). However, as clearly seen from Fig. 9, a rapid step-like decrease of $\chi_{\mathrm{N}_{2} \mathrm{O}}$ at constant $\Theta$ and thus of the $\Delta \chi_{\mathrm{N}_{2} \mathrm{O}}$ coordinate, from $\Delta \chi_{\mathrm{N}_{2} \mathrm{O}} \simeq 120 \mathrm{ppb}$ to $\Delta \chi_{\mathrm{N}_{2} \mathrm{O}}^{\text {fil }} \simeq 60-80 \mathrm{ppb}$, determines the filament boundaries more accurately. Note that for this part of the flight the potential temperature is nearly 10 constant, $\Theta \simeq 457 \mathrm{~K}$. The use of the $\Delta \chi_{\mathrm{N}_{2} \mathrm{O}}$ coordinate allows to link the filament with a particular area of the vortex boundary region in a more precise and quantitative way:

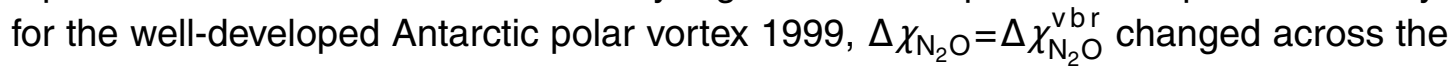
polar vortex region from $20 \mathrm{ppb}$ at the inner vortex edge to $\sim 90 \mathrm{ppb}$ near the outer vortex edge. Thus a relative position of the coordinate $\Delta \chi_{\mathrm{N}_{2} \mathrm{O}}^{\mathrm{fil}} \simeq 60-80 \mathrm{ppb}$ is well15 defined within the $\Delta \chi_{\mathrm{N}_{2} \mathrm{O}}^{\mathrm{vbr}}$ interval, and indicates an origin for this filament close to the outer vortex edge.

A position expressed in our proposed set of the coordinates, mixing ratio $\chi_{i}(\Theta)$ (the vertical coordinate) and $\Delta \chi_{\mathrm{N}_{2} \mathrm{O}}$ (the meridional, quasi-horizontal coordinate), persists over the winter polar stratosphere if (i) in a given time interval $\Delta T$ of several months, all 20 air parcels initialized at the isentropic surface $\Theta=\Theta_{\text {init }}$ undergo the same integrated diabatic descent to the surface $\Theta=\Theta_{\text {final }}$, irrespective of their horizontal, longitudinallatitudinal position, and (ii) only weak horizontal mixing occurs during the descent of the air parcels. As discussed below, this picture can be justified for the vortex boundary region in the polar Southern Hemisphere from June through August, when the Antarctic 25 vortex area is well-structured in terms of the vortex core, vortex boundary region and surf zone. Furthermore, the $\Delta \chi_{\mathrm{N}_{2} \mathrm{O}}$ coordinate is "long-lived", so that the $\left\{\chi_{\mathrm{N}_{2} \mathrm{O}}, \Delta \chi_{\mathrm{N}_{2} \mathrm{O}}\right\}$ coordinates can be used as quasi-Lagrangian in tracer-tracer $\chi_{i}: \chi_{\mathrm{N}_{2} \mathrm{O}}$ space with $\Delta \chi_{\mathrm{N}_{2} \mathrm{O}}$ parametrization of the tracer-tracer relationships.

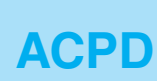

8, 16123-16173, 2008

\section{A quasi-Lagrangian coordinate system based on tracer observations}

E. V. Ivanova et al.

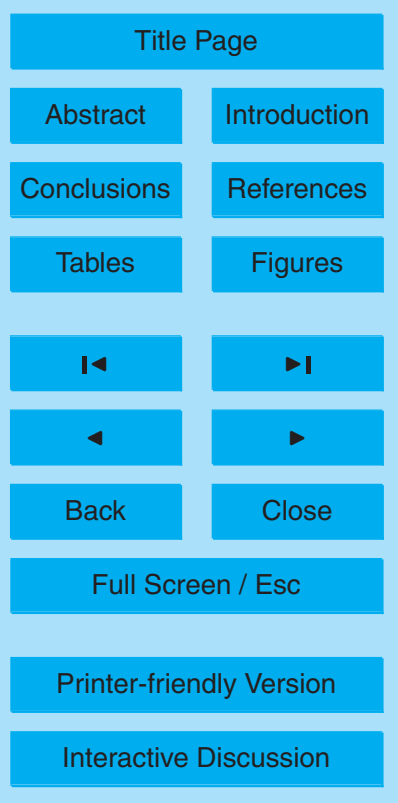


During the polar winter season, the solar light is weak. Therefore, the effective cooling, due to emission of infra-red photons, dominates over heating of the stratosphere, mainly due to the absorption by $\mathrm{O}_{3}, \mathrm{H}_{2} \mathrm{O}$ and $\mathrm{CO}_{2}$ molecules. The net cooling effect, i.e. negative heating rates, is accompanied by diabatic descent of the polar vortex (e.g., 5 Schmidt et al., 1991; Rosenfield et al., 1994). The exponential decrease of air density with increasing altitude, and the mass continuity requirement, make the rate of the diabatic descent dependent upon $\Theta$ (e.g. Ray et al., 2002): it increases with increasing potential temperature (see the vertical arrows $A A^{\prime}$ and $B B^{\prime}$ or $A_{1} A_{1}^{\prime}$ and $B_{1} B_{1}^{\prime}$ in the schematic shown in Fig. 10). For example, for the Antarctic vortex 1992, air-parcels 10 initialized in the beginning of March descended from $\Theta_{\text {init }}=600 \mathrm{~K}$ to $\Theta_{\text {final }}=420 \mathrm{~K}$, but from $\Theta_{\text {init }}=450 \mathrm{~K}$ to $\Theta_{\text {final }}=370 \mathrm{~K}$ during the same period $\Delta T=6$ months (Rosenfield et al., 1994).

In Fig. 10, the diabatic descent of the $\mathrm{N}_{2} \mathrm{O}$ trace gas is shown schematically for two different meridional locations in the Antarctic vortex boundary region. In this plot, 15 the the dashed and solid curves refer to the $\chi_{\mathrm{N}_{2} \mathrm{O}}(\Theta)$ profile: the upper dashed (solid) curve evolves to the lower dashed (solid) curve in the time interval $\Delta T$. In order to interpret the $\Delta \chi_{\mathrm{N}_{2} \mathrm{O}}$ coordinate as quasi-Lagrangian, (i) the $\Theta$-inhomogeneous polar diabatic descent should not affect the proposed coordinate system and (ii) it has to be meridionally homogeneous, i.e. the $A A^{\prime}\left(B B^{\prime}\right)$ sector should be approximately equal to the sector $A_{1} A_{1}^{\prime}\left(B_{1} B_{1}^{\prime}\right)$. In this case, the evolution of air-parcels initialized at different meridional locations $A$ and $A_{1}\left(B\right.$ and $B_{1}$ ) in a given time interval $\Delta T$ is uniquely given in terms of the $\left\{\chi_{\mathrm{N}_{2} \mathrm{O}}, \Delta \chi_{\mathrm{N}_{2} \mathrm{O}}\right\}$ coordinates: $\Delta \Theta_{A A^{\prime}}=\Delta \Theta_{A_{1} A_{1}^{\prime}}\left(\Delta \Theta_{B B^{\prime}}=\Delta \Theta_{B_{1} B_{1}^{\prime}}\right)$ and $\Delta \chi_{\mathrm{N}_{2} \mathrm{O}}^{A A_{1}}=\Delta \chi_{\mathrm{N}_{2} \mathrm{O}}^{A^{\prime} A_{1}^{\prime}}\left(\Delta \chi_{\mathrm{N}_{2} \mathrm{O}}^{B B_{1}}=\Delta \chi_{\mathrm{N}_{2} \mathrm{O}}^{B^{\prime} B_{1}^{\prime}}\right)$, as illustrated in Fig. 10 by rectangles $A A_{1} A^{\prime} A_{1}^{\prime}$ and $B B_{1} B^{\prime} B_{1}^{\prime}$. This means that the air-parcels initialized at different meridional coordinates $25 A$ and $A_{1}\left(B\right.$ and $\left.B_{1}\right)$ are equivalent to the air-parcels $A^{\prime}$ and $A_{1}^{\prime}\left(B^{\prime}\right.$ and $\left.B_{1}^{\prime}\right)$ in terms of the $\left\{\chi_{\mathrm{N}_{2} \mathrm{O}}, \Delta \chi_{\mathrm{N}_{2} \mathrm{O}}\right\}$ coordinates.

The heating rates, which are a measure of the diabatic descent, have been extensively studied for the Antarctic polar vortex area (Rosenfield et al., 1994; Hicke et al.,

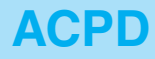

8, 16123-16173, 2008

\section{A quasi-Lagrangian coordinate system based on tracer observations}

E. V. Ivanova et al.

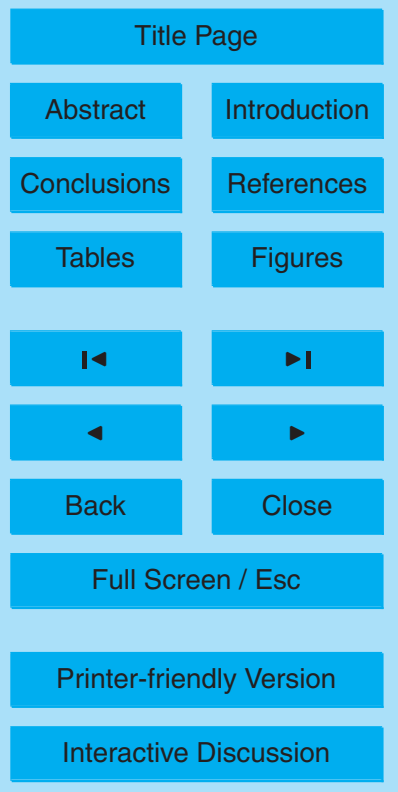


1998; Hicke and Tuck, 1999). For example, for August of 1994 the calculated Antarctic average heating rate was about $-0.35 \mathrm{~K} /$ day (in terms of the daily change of $\Theta$ ) at the $\Theta=450 \mathrm{~K}$ surface across the polar vortex boundary region (Hicke and Tuck, 1999). The local, instantanious heating rates are rather variable in the Antarctic polar vortex.

5 They depend on the location of the sea ice edge, impact of clouds, ozone mixing ratio, planetary waves activity etc. Over timescales of weeks, however, it is justified to apply average integrated heating rates that can be calculated by models (Rosenfield et al., 1994). According to the radiation models the $\Theta$-dependent time-integrated descent rates can be considered as meridionally homogeneous in the Antarctic vortex region.

10 At the same time, the horizontal mixing is rather weak in the vortex boundary region, as already discussed in this section. This concludes justification of the $\left\{\chi_{\mathrm{N}_{2} \mathrm{O}}, \Delta \chi_{\mathrm{N}_{2} \mathrm{O}}\right\}$ coordinates as quasi-Lagrangian through the polar winter for the Antarctic vortex boundary region.

As will be shown in the following sections, the use of the $\left\{\chi_{\mathrm{N}_{2} \mathrm{O}}, \Delta \chi_{\mathrm{N}_{2} \mathrm{O}}\right\}$ coordinates 15 in tracer-tracer $\chi_{i}: \chi_{\mathrm{N}_{2} \mathrm{O}}$ space allows to analyze the mixing and chemical processes in the Antarctic vortex region with no explicit reference to the coordinates (e.g., $\Theta$ and $\left.\varphi_{\mathrm{e}}\right)$ in physical space. In particular, in many cases there is even no special need to recalculate the inner vortex edge determined with the proposed approach and the quasi-Lagrangian coordinate $\Delta \chi_{i}$ in terms of the geographic latitude or equivalent lati20 tude $\varphi_{\mathrm{e}}$.

\section{Tracer-tracer relationships in the $\Delta \chi_{\mathrm{N}_{2} \mathrm{O}}$ parametrization}

The global diffuser two-dimensional model qualitatively explains how the advection and mixing processes determine the character of tracer-tracer relationships (Plumb and Ko, 1992). If local lifetimes of two trace gases under consideration, $i=1,2$, are much larger than a characteristic time needed for large-scale horizontal transport across the stratosphere, the tracer isopleths have similar shapes, a state named in Plumb and Ko (1992) as "climatological slope equilibrium" following earlier works (Holton, 1986;

A quasi-Lagrangian coordinate system based on tracer observations

E. V. Ivanova et al.

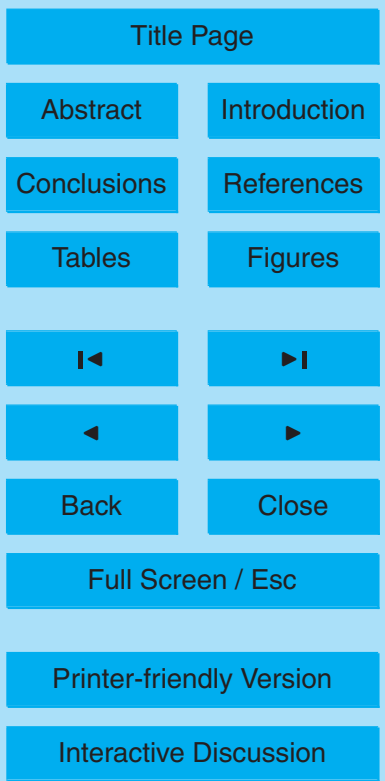

16137 
Mahlman et al., 1986). In this idealized case, at an isopleth surface $\chi_{1}=$ const the mixing ratio of the second tracer is also constant, giving rise to a compact correlation between $\chi_{1}$ and $\chi_{2}$. Initially, the model was developed under assumption of rapid meridional stratospheric transport across the globe in the absence of transport barriers. However, 5 the main equations of the model (see Eqs. 1-4 of Plumb and Ko, 1992) are local, so that the main concept of the work, the formation of compact tracer-tracer relationships, can also be applied to a stratospheric region well isolated by transport barriers (Plumb et al., 2000, 2003; Plumb, 2007), e.g., to the Antarctic vortex core.

The conditions for regular mixing (Plumb et al., 2000), which results in compact 10 tracer-tracer correlations, means that the mixing process is rapid enough in order to dominate the sources, sinks, and diabatic advection within an isolated physical space. As shown below by analyzing in-situ aircraft measurements of the long-lived trace gases in terms of the $\Delta \chi_{\mathrm{N}_{2} \mathrm{O}}$ coordinate, these conditions are normally met in the welldeveloped Antarctic vortex core.

15 The tracer-tracer relationships $\chi_{i}: \chi_{\mathrm{N}_{2} \mathrm{O}}$ obtained from the in-situ data of the APEGAIA campaign are plotted in Fig. 11 for $i=$ CFC-11, CFC-12, $\mathrm{H}-1211$ and $\mathrm{SF}_{6}$. The data points in Fig. 11 are binned and coloured in terms of the $\Delta \chi_{\mathrm{N}_{2} \mathrm{O}}$ coordinate, with $\left[\Delta \chi_{\mathrm{N}_{2} \mathrm{O}}\right]_{\text {bin }}=20 \mathrm{ppb}$. As clearly seen from Fig. 2, the values of $\chi_{\mathrm{N}_{2} \mathrm{O}}$ used in Fig. 11 cover the whole range of altitudes: values $\chi_{\mathrm{N}_{2} \mathrm{O}} \simeq 315 \mathrm{ppb}$ refer to the troposphere, 20 the interval $250 \mathrm{ppb} \lesssim \chi_{\mathrm{N}_{2} \mathrm{O}} \lesssim 315 \mathrm{ppb}$ in the polar vortex area corresponds to the subvortex (the lowermost stratosphere under the bottom of the polar vortex core; not much is known about the dynamics of air in the sub-vortex Haynes and Shuckburgh, 2000a), and the lower stratosphere is characterized by $\chi_{\mathrm{N}_{2} \mathrm{O}} \lesssim 250 \mathrm{ppb}$.

The use of $\Delta \chi_{\mathrm{N}_{2} \mathrm{O}}$-bins allows to distinguish nonlinear compact tracer-tracer rela25 tionships in various regions of the Antarctic vortex area (see Figs. 11a, $c$ and d). For example, for $\chi_{\mathrm{N}_{2} \mathrm{O}} \gtrsim 150 \mathrm{ppb}$, the blue and dark green data-points form two different curves for the CFC-11: $\mathrm{N}_{2} \mathrm{O}$ correlation which refer to the vortex core and surf zone, respectively (see Fig. 11a). The bin-coloured data-points in between these curves represent the tracer-tracer relationship within the polar vortex boundary region. For

\section{A quasi-Lagrangian coordinate system based on tracer observations}

E. V. Ivanova et al.

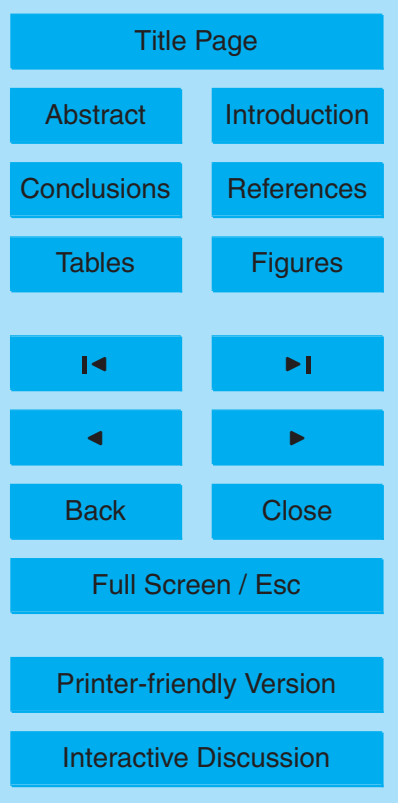

\section{8}


comparison, the correlation CFC-11: $\mathrm{N}_{2} \mathrm{O}$ at Northern middle latitudes is shown in Fig. 11a by the reference curve (black solid line).

The midlatitude reference correlation (Möbius, 2005) has been calculated for the Northern Hemisphere by using data sampled with the balloon-borne cryogenic whole 5 air sampler (Schmidt et al., 1987; Engel et al., 1997) during balloon research flights carried out from Aire-sur-l'Adour $\left\{43.7^{\circ} \mathrm{N}, 0.25^{\circ} \mathrm{W}\right\}$ and Gap-Tallard $\left\{44.45^{\circ} \mathrm{N}, 6.03^{\circ} \mathrm{E}\right\}$. The reference line should be compared with the points from the bin $\Delta \chi_{\mathrm{N}_{2} \mathrm{O}}>90 \mathrm{ppb}$ of the CFC-11: $\mathrm{N}_{2} \mathrm{O}$ inter-relationship inferred from the APE-GAIA data (see green triangular markers in Fig. 11a). The latter bin refers to midlatitude air in the Southern 10 Hemisphere. As clearly seen in Fig. 11a, the CFC-11: $\mathrm{N}_{2} \mathrm{O}$ correlations practically coincide in the midlatitude lowermost southern and northern stratosphere areas. The correlations, however, start to be different at higher altitudes, for $\chi_{\mathrm{N}_{2} \mathrm{O}} \lesssim 250-270 \mathrm{ppb}$ (see Fig. 11a). The asymmetry of the midlatitude tracer-tracer correlation functions measured in both hemispheres is discussed in the literature (e.g., Morgenstern and 15 Pyle, 2003).

Theory of the formation of compact canonical tracer interrelationships, which develop for every stratospheric region separated by transport barriers, is given in Plumb (2007). During the setup period of the polar vortex the conditions for regular mixing are not met: isentropic mixing is not rapid enough to balance frequent intrusions of midlatitude air into the vortex core. The latter process is known in the literature as an event of anomalous mixing (e.g., Waugh et al., 1997; Plumb et al., 2000; Ray et al., 2002). The anomalous mixing can lead to increased scatter on the concave side of curved, initially compact tracer interrelationships. Subsequent rapid isentropic mixing within the vortex core results in tracer-tracer relationships that are compact but less curved than the initial ones. Anomalous isentropic mixing of differentially descended air masses within the vortex core is another mechanism causing deviation from the compactness and the subsequent linearization of the tracer interrelationships (e.g., Michelsen et al., 1998; Ray et al., 2002; Morgenstern et al., 2002; Plumb et al., 2003; Lemmen et al., 2006). The evolution of compact tracer relation curves in the polar vortices less

\section{A quasi-Lagrangian coordinate system based on tracer observations}

E. V. Ivanova et al.

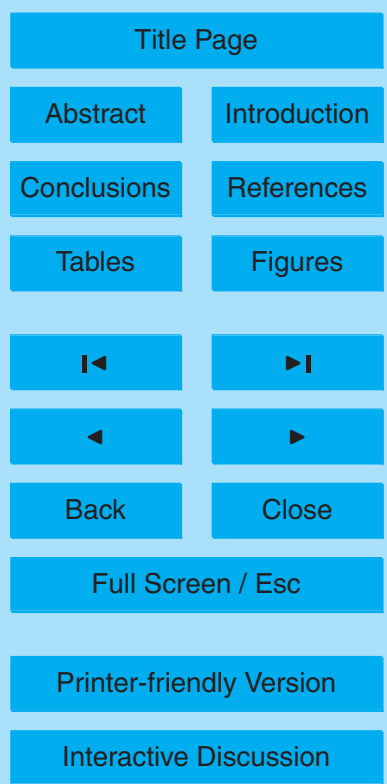


curved than those at midlatitudes (from which they evolve) is a result of both the above anomalous mixing processes, although it is generally difficult to say which process dominates (Plumb, 2007). The APE-GAIA observations show a gradual (meridional) progression from non-linear midlatitude curves to more linear vortex curves across the 5 vortex boundary region, which is most clearly illustrated in Fig. 10a: with decreasing $\Delta \chi_{\mathrm{N}_{2} \mathrm{O}}$ the correlation curve in Fig. 10a shifts to the left, i.e. becomes more linear. The most linear section of the curve consists of the blue circled data-points, which in the interval $140 \mathrm{ppb} \lesssim \chi_{\mathrm{N}_{2} \mathrm{O}} \lesssim 250 \mathrm{ppb}$ are attributed to the Antarctic vortex core. For CFC12 (see Fig. 11b) one cannot observe this structure because of the intrinsically linear 10 character of CFC-12: $\mathrm{N}_{2} \mathrm{O}$ correlation in the lower stratosphere. For $\mathrm{H} 1211$ and $\mathrm{SF}_{6}$ (see Figs. 11c and d), the structure is somewhat obscured by the inferior precision of the measurements, but in either case the correlation curves belonging to the vortex core are located toward the concave side of the whole ensemble.

The observed meridional structure of the tracer relation curves suggests that the 15 above processes which tend to linearize the initial correlation curves act more strongly or for a longer duration in the vortex core. It is likely that anomalous mixing is most efficient during the early phase of the vortex, resulting in the formation of correlation curves for the vortex region (not necessarily compact ones) which lie on the concave side of the midlatitude curves. We suggest that when the vortex is fully developed, 20 i.e. in the absence of rapid mixing in the boundary region, the curves belonging to the outer vortex region do not evolve further, but remain "frozen" at an intermediate or incomplete state of mixing. In the vortex core, however, further linearization of the correlation curves might be a process continuing throughout the lifetime of the vortex, albeit likely at a slower pace than during setup. While anomalous mixing between the 25 vortex boundary region and the surf zone can probably occur through the outer vortex edge (Waugh et al., 1997; Plumb et al., 2000; Plumb, 2002), the vortex core of the well-developed Antarctic vortex remains isolated and is not considerably affected by anomalous mixing between the vortex core and the vortex boundary region through the inner vortex edge (e.g., Chen, 1994). Thus any continuing linearization of tracer

A quasi-Lagrangian coordinate system based on tracer observations

E. V. Ivanova et al.

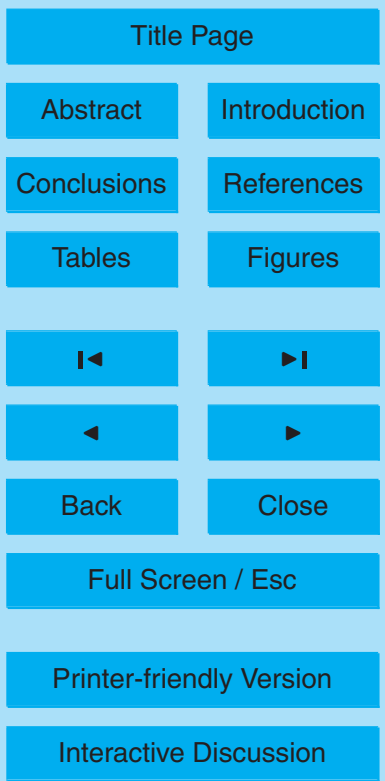

\section{0}


relation curves in the vortex core can only be caused by anomalous mixing within the core itself. In the following section we present evidence that such anomalous mixing indeed occurs in the Antarctic vortex core in October 1999.

\section{Solitary anomalous points in the Antarctic tracer- $\mathrm{N}_{2} \mathrm{O}$ correlations: evidence of vertical mixing} 5

Five "anomalous" points marked by $1-5$ in Figs. 11 and 12, which were measured during the research flight on 12 October 1999 (APE-GAIA campaign), illustrate how lower stratospheric air isolated in the vortex core tends to evolve towards a state characterized by compact and linear tracer-tracer inter-relationships. The data-points 1-5 are 10 located along the straight line (see Fig. 12) to which the CFC-11: $\mathrm{N}_{2} \mathrm{O}$ vortex correlation curve would evolve through continuous mixing if the vortex were to persist for a much longer time. Such anomalous points have also been observed in other field campaigns. For example, a solitary anomalous point was detected for the CFC-11: $\mathrm{N}_{2} \mathrm{O}$ relationship during the ASHOE campaign (Waugh et al., 1997; Volk et al., 1997) during 15 research flight on 3 March 1994 (see point 6 in Fig. 13). The anomalous point 6 was measured in June at $\Theta \simeq 455 \mathrm{~K}$, while the anomalous point 1 was detected in October at $\Theta \simeq 417 \mathrm{~K}$ (see Figs. 12 and 13). This potential temperature difference reflects the large-scale diabatic descent of the Antarctic vortex during the austral winter.

Figure 12 shows that the anomalous points lie along a straight hypothetical mixing

20 line in the CFC-11: $\mathrm{N}_{2} \mathrm{O}$ scatter plot connecting regions with very distinct potential temperatures $\left(\left.\Theta\right|_{A} \simeq 440 \mathrm{~K} ;\left.\Theta\right|_{B} \simeq 385 \mathrm{~K} ;\left.\Theta\right|_{C} \simeq 410 \mathrm{~K} ;\left.\Theta\right|_{D} \simeq 430 \mathrm{~K}\right)$. Thus the points 1-5 cannot be explained by any type of isentropic mixing, be it mixing of the extra vortex air into the vortex core or mixing between differentially descended air-parcels within the vortex core, as was proposed in e.g., Ray et al. (2002) and Müller et al. 25 (2005) for the Arctic vortex. Instead the process at work here appears to truly mix across isentropes separated by tens of K. Cross-isentropic dispersion may generally occur in the stratosphere due to local small-scale mixing across isentropes by sporadic

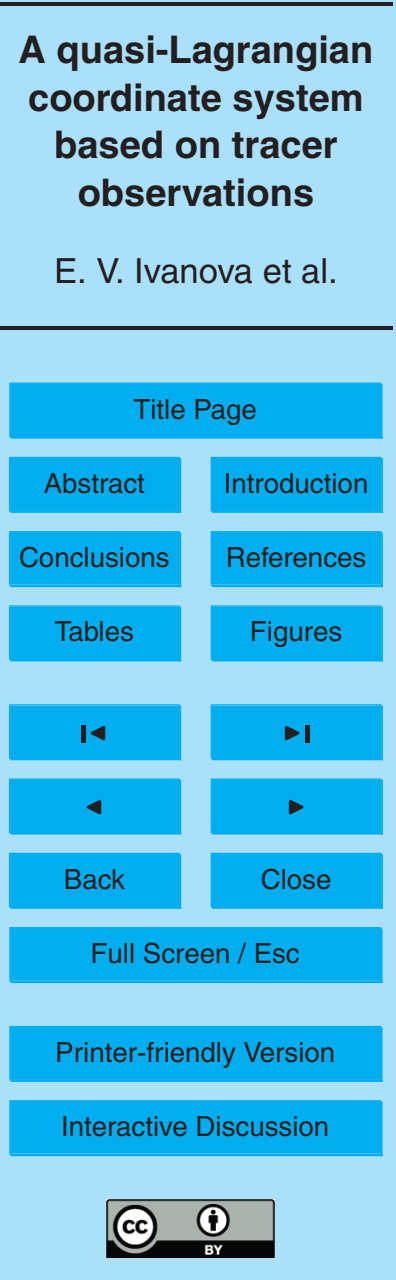


three-dimensionally turbulent layers (e.g., Dewan, 1981).

Because the anomalous points are solitary in the sequence of the flight measurements, the width of the regions in question, evaluated from the average aircraft velocity, is indeed relatively small, $\sim 40 \mathrm{~km}$ only.

$5 \quad$ Sporadic three-dimensional small-scale turbulent mixing results in particular also from breaking gravity waves. This is not an unlikely cause for the anomalous points observed during APE-GAIA, given the observations were made above the Antarctic Peninsula where Lee waves are common and were indeed confirmed to be present during the flight on 2 October 1999 (Cairo et al., 2004). However the anomalous point 106 in Fig. 13 cannot be explained in this way.

The anomalous points are both a sporadic and transient phenomenon: The air parcels with anomalous mixing ratio will eventually be absorbed by surrounding air and the anomalous points in the CFC-11: $\mathrm{N}_{2} \mathrm{O}$ correlation will disappear. This process can be seen as a minor step in the linearization of the correlation in the well-developed 15 Antarctic vortex core. Generally, the linearization of the tracer-tracer relationships in the Antarctic polar vortex core is rather effective during the setup phase, due to the processes mentioned in Sect. 4. Further evolution towards linear correlations within the well-developed Antarctic vortex may be due to vertical dispersion caused by isentropic mixing of differentially descended air (Plumb, 2007). We suggest that sporadic small-scale three-dimensional turbulent mixing as apparent from the anomalous points also contributes to this linearization. However, in a bulk sense these processes are slow and cause only small changes in the tracer-tracer correlations formed in the polar vortex core during the setup period. A complete linearization of the correlation curves is not expected to be completed within the vortex lifetime. However, in the case of the CFC-11: $\mathrm{N}_{2} \mathrm{O}$ correlation observed during APE-GAIA, continued mixing in the vortex core has apparently resulted in a correlation curve that is nearly linear from the tropopause up to $\Theta \simeq 450 \mathrm{~K}\left(\chi_{\mathrm{N}_{2} \mathrm{O}} \simeq 130 \mathrm{ppb}\right)$ by the end of the Antarctic winter 1999 (see Figs. 11a and 12). This may suggest that mixing is more efficient in the lower stratosphere than at higher altitudes, for which the correlation remains curved.

A quasi-Lagrangian coordinate system based on tracer observations

E. V. Ivanova et al.

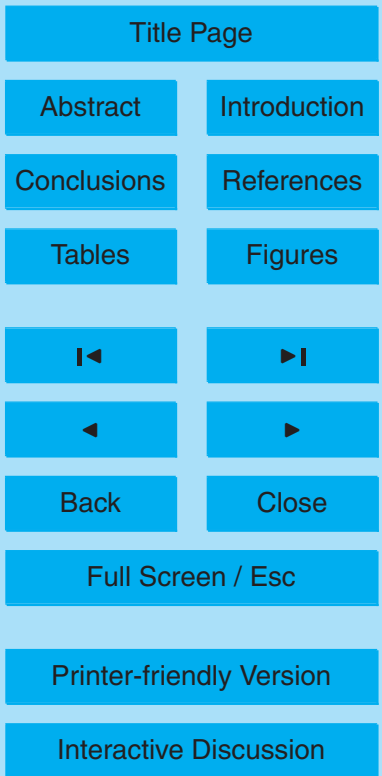


The anomalous points $1-5$ correspond to nearly zero values of the $\mathrm{H}-1211$ mixing ratio in the $\mathrm{H} 1211$ : $\mathrm{N}_{2} \mathrm{O}$ correlation (see Fig. 11c), so that the vertical mixing described above cannot be visualized for this tracer. It can also hardly be quantified for the $\mathrm{SF}_{6}: \mathrm{N}_{2} \mathrm{O}$ relationship (see Fig. 11d), due to the small curvature of the correlation 5 curve and the rather noisy $\mathrm{SF}_{6}$ signal.

The CFC-12: $\mathrm{N}_{2} \mathrm{O}$ correlation is intrinsically linear for the $\mathrm{N}_{2} \mathrm{O}$ mixing ratio (vertical coordinate) for the interval $100 \mathrm{ppb} \lesssim \chi_{\mathrm{N}_{2} \mathrm{O}} \lesssim 315 \mathrm{ppb}$, as illustrated in Fig. $11 \mathrm{~b}$, due to a rather small difference between the atmospheric lifetimes of these species $(\simeq 100$ years for CFC-12 against $\simeq 120$ years for $\mathrm{N}_{2} \mathrm{O}$ ).

\section{$6 \mathrm{H}_{2} \mathrm{O}$ distribution in the Antarctic polar area: isolation of the vortex core and determining of the outer vortex edge}

There is one particular component of stratospheric air, water vapour, that allows to find both the inner and outer vortex edges in the lower southern stratosphere by applying the $\delta \chi$-criterion.

15 Due to the oxidation of methane, in the stratosphere above the hygropause, where the water vapour minimum occurs, the mixing ratios $\chi_{\mathrm{H}_{2} \mathrm{O}}$ and $\chi_{\mathrm{CH}_{4}}$ anticorrelate (e.g., Engel et al., 1996). In the lower stratosphere outside the polar vortex, a source of $\mathrm{H}_{2} \mathrm{O}$, which gives a relatively low $\chi_{\mathrm{H}_{2} \mathrm{O}}$, is due to vertical and horizontal transport from the troposphere to the lower stratosphere (Fueglistaler et al., 2005; Tian and Chipperfield, 2006). In this case, the water vapour ascends in the tropics and then moves polewards being driven by the Brewer-Dobson circulation. The $\mathrm{H}_{2} \mathrm{O}$ mixing ratio against the potential temperature $\Theta$, as measured by the FLASH (Fluorescent Airborne Stratospheric Hygrometer, Sitnikov et al., 2007) in the Southern Hemisphere during the APE-GAIA campaign, is plotted in Fig. 14.

25 During the Southern Hemisphere winter, air from the middle and upper stratosphere with high $\chi_{\mathrm{H}_{2} \mathrm{O}}$, due to the $\mathrm{CH}_{4}$ oxidation process, descends resulting in humid air within the vortex area in the lower stratosphere. If the Antarctic polar vortex is well-developed,

A quasi-Lagrangian coordinate system based on tracer observations

E. V. Ivanova et al.

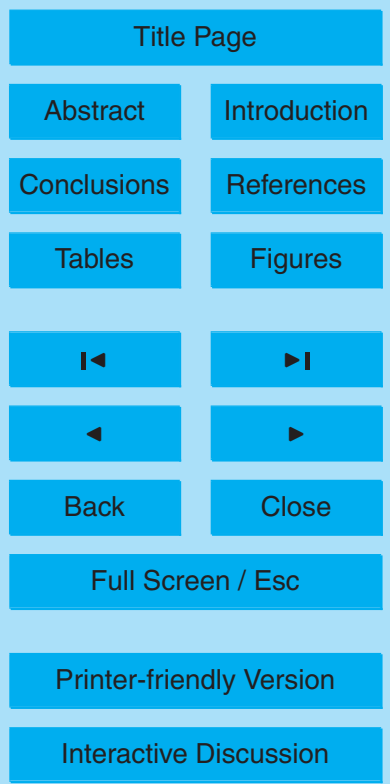

6143 
the mixing ratio $\chi_{\mathrm{H}_{2} \mathrm{O}}$ can be by about a factor 2 higher in the vortex boundary region compared to its surrounding areas, the vortex core and surf zone (see Figs. 15 and 17).

Polar stratospheric clouds (PSCs) are effectively formed within the cold vortex core. 5 The following sedimentation of the PSCs results in the dehydration of the stratospheric vortex core (a rather small coldest part of the Antarctic vortex core - of about $10-25 \%$ of the total vortex core area - is able to trigger the dehydration process Vömel et al., 1995). At the same time, air outside the vortex core and the vortex boundary region, i.e. in the surf zone, remains relatively dry. Such a scenario (Lee et al., 2001) explains 10 qualitatively the existence of $\mathrm{H}_{2} \mathrm{O}$-rich lower stratospheric air in the vortex boundary region. All the transient processes associated with dehydration, e.g., rehydration, are completed by the end of July. As a result, $\mathrm{H}_{2} \mathrm{O}$ vapour can be considered as a welldefined conservative trace gas from the beginning of August through to the middle of October (Vömel et al., 1995).

15 The distribution of the mixing ratio $\chi_{\mathrm{H}_{2} \mathrm{O}}$ across the well-developed Antarctic vortex as described above was clearly observed in all the research flights of the APE-GAIA campaign: $\chi_{\mathrm{H}_{2} \mathrm{O}}(\Theta)$ is plotted in Fig. 15 by using the $\Delta \chi_{\mathrm{N}_{2} \mathrm{O}}$ parametrization. As illustrated in Fig. 15, during the austral winter the humid vortex boundary region of the Antarctic lower stratosphere is surrounded by the drier vortex core and surf zone. This clearly confirms the isolation of the Antarctic vortex core. Note that in this case the $\Delta \chi_{\mathrm{N}_{2} \mathrm{O}}$ parametrization again allows to distinguish, by quantifying $\chi_{\mathrm{H}_{2} \mathrm{O}}$, three main regions of the Antarctic vortex area.

The $\delta \chi$-criterion can be used to identify the inner and outer vortex edges by attributing them to the $\delta$-step $\delta_{\chi_{\mathrm{H}_{2} \mathrm{O}}}^{\text {in }}$ (inner edge) and to the local minimum of $\nabla \chi_{\mathrm{H}_{2} \mathrm{O}}$ (outer 25 edge) in the $\chi_{\mathrm{H}_{2} \mathrm{O}}$-distribution along an isentropic surface that crosses the Antarctic vortex boundary region (Ivanova et al., 2006; Ivanova, 2007). This is illustrated by the schematic shown in Fig. 16, where $x$ is latitudinal coordinate and the outer vortex edge

\section{A quasi-Lagrangian coordinate system based on tracer observations}

E. V. Ivanova et al.

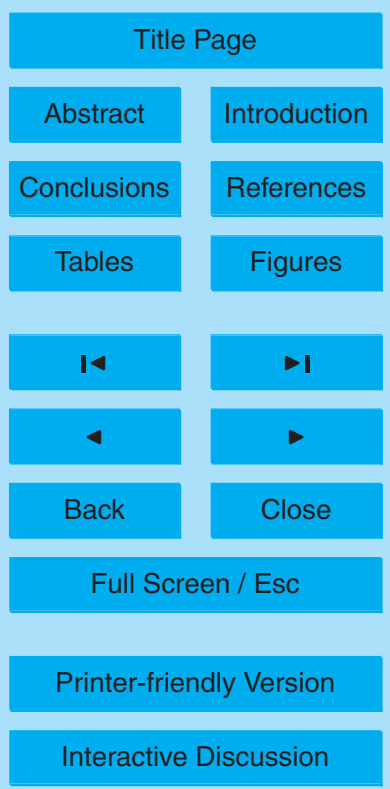


is defined by the condition:

$\left.\frac{\partial \chi_{\mathrm{H}_{2} \mathrm{O}}}{\partial x}\right|_{\Theta=\text { const }}=$ Min .

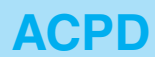

A rapid change of the mixing ratio $\chi_{\mathrm{H}_{2} \mathrm{O}}$ across the inner vortex edge, from $3 \mathrm{ppm}$ to $2.2 \mathrm{ppm}$, has been reported (Yushkov et al., 2001; Ulanovskii et al., 2004). In this case 5 the step $\delta_{\chi_{\mathrm{H}_{2} \mathrm{O}}}^{\text {in }} \simeq 0.8 \mathrm{ppm}$ occurs in less than $70 \mathrm{~km}$ latitudinal distance (Ulanovskii et al., 2004). Below, the $\delta \chi$-method is illustrated for finding both the inner and outer vortex edges from $\chi_{\mathrm{H}_{2} \mathrm{O}}$ measured in one flight across the Antarctic polar vortex boundary region.

The $\mathrm{H}_{2} \mathrm{O}$ mixing ratio $\chi_{\mathrm{H}_{2} \mathrm{O}}$ measured with $\mathrm{FLASH}$ in the research flight on 21 10 September of the APE-GAIA campaign is plotted in Fig. 17 against (a) the flight time and (b) the equivalent latitude $\varphi_{\mathrm{e}}$. The vortex boundary region with steps $\delta_{\chi_{\mathrm{H}_{2} \mathrm{O}}}^{\text {in }} \simeq 0.9 \mathrm{ppm}$ and $\delta_{\chi_{\mathrm{H}_{2} \mathrm{O}}}^{\text {out }} \simeq 0.6 \mathrm{ppm}$ can clearly be identified. The $\Delta \chi_{\mathrm{N}_{2} \mathrm{O}}$ coordinate, which is shown in Fig. $17 \mathrm{a}$ by the blue solid line, has the $\delta_{\chi_{\mathrm{N}_{2} \mathrm{O}}}$-step exactly at the same place where the $\delta_{\chi_{\mathrm{H}_{2} \mathrm{O}}}^{\text {in }}$-step occurs. This proves high stability and efficiency of 15 the $\delta \chi$-criterion.

Figure $17 \mathrm{~b}$ clearly shows that the $\delta \chi$-criterion and $\Delta \chi$-method, both based on locally measured $\chi_{\mathrm{H}_{2} \mathrm{O}}$ give a more accurate definition of the outer vortex edge than the Nash criterion (compare the right-hand side dash-dotted line, which refers to the outer vortex edge according to the Nash criterion, with the location of the $\nabla \chi_{\mathrm{H}_{2} \mathrm{O}}$ minimum).

\section{Conclusions}

The two-dimensional coordinate system $\left\{\chi_{i}, \Delta \chi_{i}\right\}$ introduced in our study is based on a trace gas $i$ and refers to a well-developed polar vortex. In this coordinate system the mixing ratio $\chi_{i}$ of a long-lived tracer is the vertical coordinate and the isentropic "tracer distance" from the vortex core $\Delta \chi_{i}(\Theta)=\chi_{i}(\Theta)-\chi_{i}^{\text {vort }}(\Theta)$ is the meridional coordinate.

A quasi-Lagrangian coordinate system based on tracer observations

E. V. Ivanova et al.

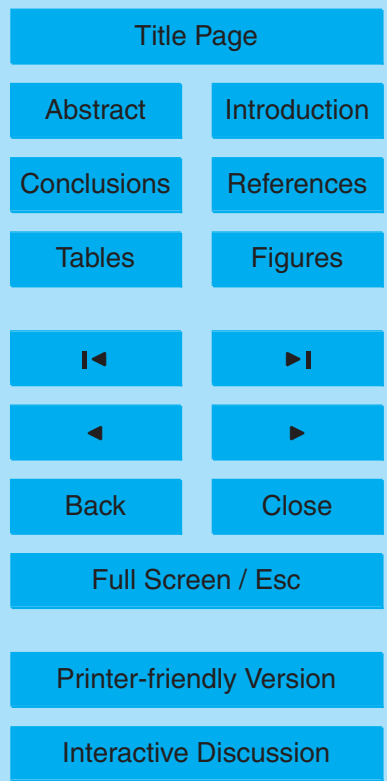


These coordinates can be measured in-situ at high resolution, persist for a much longer period of time compared with the standard isentropic coordinates (potential temperature $\Theta$ and equivalent latitude $\varphi_{\mathrm{e}}$ ), and do not require explicit reference to geographic space. The proposed $\left\{\chi_{i}, \Delta \chi_{i}\right\}$ coordinate system is thus quasi-Lagrangian 5 over the course of a polar winter and is therefore well-suited for studying the dynamics of the Antarctic polar vortex and the relevant ozone loss processes (Ivanova et al., 2008) ${ }^{1}$. More generally, the parametric coordinate system $\left\{\chi_{i}, \Delta \chi_{i}\right\}$ is useful in characterizing the evolution in the polar vortex of any observed quantity whose spatial distribution is heavily influenced by transport, e.g. also aerosol particles (Curtius et al., 2005). The following conclusions summarize our results.

(i) The in-situ measurements of the APE-GAIA campaign are analyzed in terms of the quasi-Lagrangian coordinates $\left\{\chi_{\mathrm{N}_{2} \mathrm{O}}, \Delta \chi_{\mathrm{N}_{2} \mathrm{O}}\right\}$, i.e. for the trace gas $i=\mathrm{N}_{2} \mathrm{O}$. In this case, the reference profile $\chi_{i}^{\text {vort }}=\chi_{i}^{\text {vort }}(\Theta)$, which is compact in a well-developed and isolated polar vortex core (Greenblatt et al., 2002), is constructed by combining the 15 relevant measurements of the research flights on 21 and 23 September, and on 2 and 12 October, 1999 together with high-altitude satellite data of ILAS-II (Improved Limb Atmospheric Spectrometer - II). The $\Delta \chi_{\mathrm{N}_{2} \mathrm{O}}$ parametrization, i.e. the use of the quasiLagrangian meridional coordinate $\Delta \chi_{\mathrm{N}_{2} \mathrm{O}}$, allows to determine the polar vortex core by $\Delta \chi_{\mathrm{N}_{2} \mathrm{O}} \lesssim 20 \mathrm{ppb}$, the polar vortex boundary by $20 \mathrm{ppb} \lesssim \Delta \chi_{\mathrm{N}_{2} \mathrm{O}} \lesssim 80 \mathrm{ppb}$, and the surf 20 zone by $\Delta \chi_{\mathrm{N}_{2} \mathrm{O}} \gtrsim 80 \mathrm{ppb}$.

(ii) The frequently used Nash criterion for determining the inner and outer vortex edges, $\varphi_{\mathrm{e}}^{\text {i.v.e. }}$ and $\varphi_{\mathrm{e}}^{\text {o.v.e. }}$, as zero-points of the third derivative of the potential vorticity $P$ with respect to the equivalent latitude coordinate $\varphi_{\mathrm{e}}$ is based on a meteorological analysis of the global stratospheric dynamics. We have shown that this method is less accurate than using the local in-situ measurements of $\chi_{i}=\chi_{i}(\Theta)$ and attributing the inner vortex edge to a rapid change $\left(\delta\right.$-step) in the meridional profile of the mixing ratio $\chi_{i}$,

\footnotetext{
${ }^{1}$ Ivanova, E. V., Volk, C. M., Ulanovskii, A. E., et al.: Ozone Distribution in the Antarctic
} Vortex Boundary Region as a Function of $\Delta \chi_{\mathrm{N}_{2} \mathrm{O}}$, Geophys. Res. Lett., in preparation, 2008.

\section{A quasi-Lagrangian coordinate system based on tracer observations}

E. V. Ivanova et al.

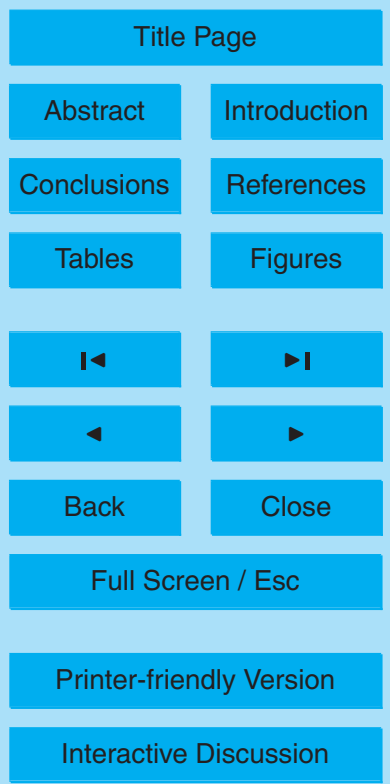


associated with the trace gas $i$, at an isentropic surface $\Theta=$ const.

For the cases examined here, the difference between the latitude positions of the Antarctic inner vortex edge found using the Nash criterion and by means of the $\delta_{\chi_{\mathrm{N}_{2} \mathrm{O}}}$ step was as large as $100-200 \mathrm{~km}$. We propose to determine the outer vortex edge of

5 a well-developed Antarctic vortex as the position of a local minimum of the meridional gradient $\nabla \chi_{\mathrm{H}_{2} \mathrm{O}}$ in the vortex region. The described criteria for accurate determination of the inner and outer edges of the Antarctic polar vortex, which are based on the local stratospheric dynamics, require, however, isentropic meridional cross-sections of the vortex edge by in-situ measurements of the trace gases.

10 (iii) For the well-developed Antarctic vortex, the parametrization of tracer-tracer correlations in terms of the meridional coordinate $\Delta \chi_{\mathrm{N}_{2} \mathrm{O}}$ allows to distinguish the tracer inter-relationships in the vortex core, vortex boundary region and surf zone. This is clearly illustrated by analyzing the tracer-tracer relationships $\chi_{i}: \chi_{\mathrm{N}_{2} \mathrm{O}}$ obtained from the in-situ data of the APE-GAIA campaign for $i=\mathrm{CFC}-11, \mathrm{CFC}-12, \mathrm{H}-1211$ and $\mathrm{SF}_{6}$. 15 Compactness of the $\chi_{\mathrm{N}_{2} \mathrm{O}}: \Theta$ correlation (Greenblatt et al., 2002), and of the tracertracer relationships $\chi_{i}: \chi_{\mathrm{N}_{2} \mathrm{O}}$ within the vortex core shows that the Antarctic vortex core is well-mixed. The distribution of the $\mathrm{H}_{2} \mathrm{O}$ mixing ratio in terms of the $\Delta \chi_{\mathrm{N}_{2} \mathrm{O}}$ parametrization confirms that the vortex core of the well-developed Antarctic vortex remains isolated and is not considerably affected by anomalous mixing between the 20 vortex core and the vortex boundary region through the inner vortex edge. In particular, the vortex core is thus well-separated from the surf zone by the vortex boundary region which forms a nearly impermeable transport barrier in the lower stratosphere, in concurrence with the conclusion of (Lee et al., 2001). The observed tracer-tracer correlations in the vortex boundary region become increasingly linear with decreasing distance from the vortex core. While the linearization of the tracer-tracer correlations in the Antarctic vortex region is likely most effective until the beginning of the Austral winter, the evolution towards linear correlations within the core of the well-developed polar vortex continues slowly throughout the winter due to cross-isentropic dispersion (Plumb, 2007). Our observations during APE-GAIA campaign show that by the end

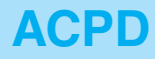

$8,16123-16173,2008$

A quasi-Lagrangian coordinate system based on tracer observations

E. V. Ivanova et al.

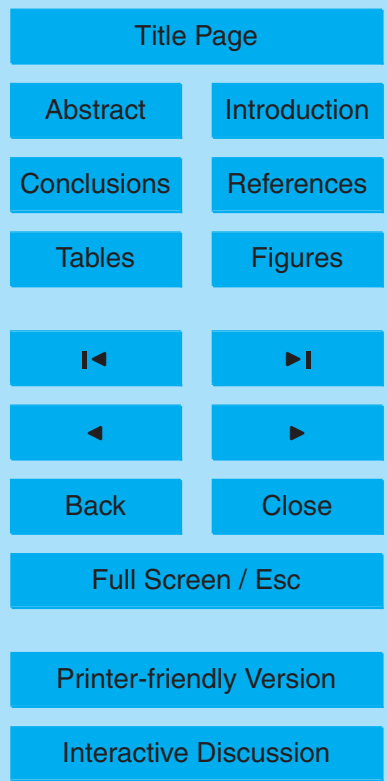


of the winter 1999 such dispersion processes have nearly completely linearized the CFC-11: $\mathrm{N}_{2} \mathrm{O}$ correlation in the vortex core from the tropopause up to $\Theta \simeq 450 \mathrm{~K}$ $\left(\chi_{\mathrm{N}_{2} \mathrm{O}} \simeq 130 \mathrm{ppb}\right)$.

(iv) A number of solitary anomalous points in the CFC-11: $\mathrm{N}_{2} \mathrm{O}$ correlation, ob5 served within the Antarctic vortex core during the APE-GAIA and ASHOE campaigns, are interpreted as a result of vertical mixing due to small-scale three-dimensional turbulence, in the case of APE-GAIA possibly caused by breaking gravity waves above the Antarctic Peninsula. The position of these anomalous points in tracer-tracer space demonstrates that such vertical mixing has a tendency to linearize the CFC-11: $\mathrm{N}_{2} \mathrm{O}$ 10 relationship. The anomalous points are transient and subsequent isentropic mixing with surrounding air is expected to re-establish a single compact, though slightly more linear, correlation in the vortex core. While the net effect of any such single small-scale vertical mixing event on the total CFC-11: $\mathrm{N}_{2} \mathrm{O}$ correlation is expected to be very small, we suggest that these sporadic events might overall significantly contribute to a contin15 ued slow cross-isentropic dispersion and associated linearization of tracer relations in the isolated vortex core throughout the lifetime of the vortex.

Acknowledgements. We thank Martin Strunk for his contribution to constructing and operating the HAGAR instrument. We thank Simone Tilmes for providing $\mathrm{N}_{2} \mathrm{O}$ satellite data and producing vertical profile and gratefully acknowledge the contribution of all members of the Improved Limb Atmospheric Spectrometer (ILAS-II). We are also thankful to the entire team of the M55 Geophysica aircraft. We finally gratefully acknowledge support of the APE-GAIA campaign by Programma Nazionale di Ricerche in Antartide (PNRA), Italy, and Agenzia Spaziale Italian (ASI), Italy, Consiglio Nazionale delle Ricerche (CNR), Italy, and support by the Bundesministerium für Bildung und Forschung (BMBF), Germany, for the HAGAR team.

\section{References}

Butchart, N. and Remsberg, E. E.: The area of the stratospheric polar vortex as a diagnostic for tracer transport on an isentropic surface, J. Atmos. Sci., 43, 1319-1339, 1986. 16126

A quasi-Lagrangian coordinate system based on tracer observations

E. V. Ivanova et al.

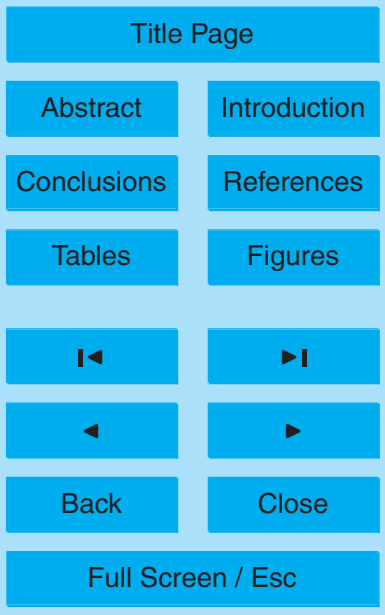

Printer-friendly Version

Interactive Discussion 
Cairo, F., Adriani, A., Viterbini, M., Di Donfrancesco, G., Mitev, V., Matthey, R., Bastiano, M., Redaelli, G., Dragani, R., Ferretti, R., Rizi, V., Paolucci, T., Bernardini, L., Cacciani, M., Pace, G., and Fiocco, G.: Polar stratospheric clouds observed during the Airborne Polar Experiment - Geophysica Aircraft in Antarctica (APE-GAIA) campaign, J. Geophys. Res., 109, D07204, doi:10.1029/2003JD003930, 2004.

Carli, B., Cortesi, U., Blom, C. E., Chipperfield, M. P., De Rossi, G., and Redaelli, G.: Airborne Polar Experiment - Geophysica Aircraft in Antarctica (APE-GAIA), SPARC Newsletter, 15, 21-24, 2000. 16124, 16127, 16128

Chen, P.: The permeability of the Antarctic vortex edge, J. Geophys. Res., 99, 563-571, 1994. 16140

Coy, L., Nash, E. R., and Newman, P. A.: Meteorology of the polar vortex: Spring 1997, Geophys. Res. Lett., 24, 2693-2696, 1997. 16130

Curtius, J., Weigel, R., Vössing, H.-J., Wernli, H., Werner, A., Volk, C.-M., Konopka, P., Krebsbach, M., Schiller, C., Roiger, A., Schlager, H., Dreiling, V., and Borrmann, S.: Observations of meteoric material and implications for aerosol nucleation in the winter Arctic lower stratosphere derived from in situ particle measurements, Atmos. Chem. Phys., 5, 3053-3069, 2005, http://www.atmos-chem-phys.net/5/3053/2005/. 16146

Dewan, M. E.: Turbulent vertical transport due to thin intermittent mixing layers in the stratosphere and other stable fluids, Science, 211, 1041-1042, 1981. 16142

20 Engel, A., Schiller, C., Schmidt, U., Borchers, R., Ovarlez, H., and Ovarlez, J.: The total hydrogen budget in the Arctic winter stratosphere during the European Arctic Stratospheric Ozone Experiment, J. Geophys. Res., 101, 14495-14503, 1996. 16143

Engel, A., Schmidt, U., and Stachnik, R. A.: Partitioning between chlorine reservoir species deduced from observations in the Arctic winter stratosphere, J. Atmos. Chem., 27, 107-126, 1997. 16139, 16167

Ertel, H.: Ein neuer hydrodynamischer Erhaltungssatz, Naturwissentschaften, 30, 543-544, 1942. 16125

Fahey, D. W., Solomon, S., Kawa, S. R., Loewenstein, M., Podolske, J. R., Strahan, S. E., and Chan, K. R.: A diagnostic for denitrification in the winter polar stratospheres, Nature, 345, 698-702, doi:10.1038/345698a0, 1990. 16126

Fueglistaler, S., Bonazzola, M., Haynes, P. H., and Peter, T.: Stratospheric water vapor predicted from the Lagrangian temperature history of air entering the stratosphere in the tropics, J. Geophys. Res., 110, D08107, doi:10.1029/2004JD005516, 2005. 16143

\section{A quasi-Lagrangian coordinate system based on tracer observations}

E. V. Ivanova et al.

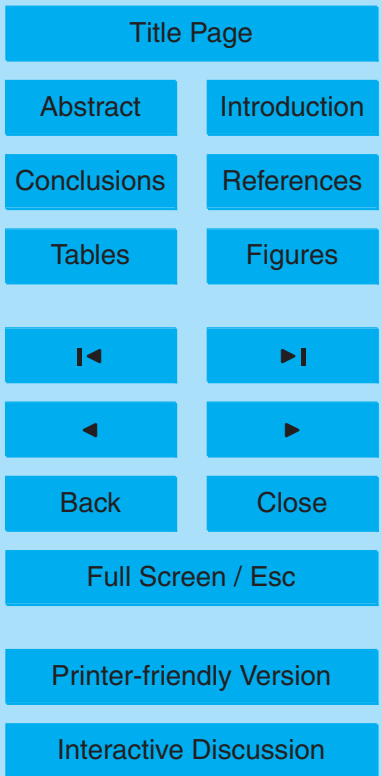

16149 
Haynes, P. H.: Transport, stirring and mixing in the atmosphere, in: Mixing: chaos and turbulence, proceedings NATO ASI Cargese July 1996, edited by: Chate, H., Villermaux, E., and Chomaz, J.-M., Kluwer Academic/Plenum, New York, 229-272, 1999. 16131

Haynes, P. and Shuckburgh, E.: Effective diffusivity as a diagnostic of atmospheric transport: 1. Stratosphere, J. Geophys. Res., 105, 22 777-22 794, 2000a. 16125, 16138

Haynes, P. and Shuckburgh, E.: Effective diffusivity as a diagnostic of atmospheric transport: 2. Troposphere and lower stratosphere, J. Geophys. Res., 105, 22 795-22 810, 2000b. 16125

Hicke, J., Tuck, A., and Smith, W.: A comparison of Antarctic stratospheric radiative heating rates calculated from high-resolution interferometer sounder and UK Meteorological Office 10 data, J. Geophys. Res., 103, 19691-19707, 1998. 16136

Hicke, J. and Tuck, A.: Tropospheric clouds and lower stratospheric heating rates: Results from late winter in the Southern Hemisphere, J. Geophys. Res., 104, 9309-9324, 1999. 16137

Holton, J. R.: A dynamically based transport parametrization for one-dimensional photochemical models of the stratosphere, J. Geophys. Res., 91, 2681-2686, 1986. 16137

Gao, R. S., Poop, P. J., Ray, E. A., Rosenlof, K. H., Northway, M. J., Fahey, D. W., Tuck, A. F., Webster, C. R., Hurst, D. F., Chauffler, S. M., Jost, H., and Bui, T. P.: Role of $\mathrm{NO}_{y}$ as a diagnostic of small-scale mixing in a denitrified polar vortex, J. Geophys. Res., 107, 4794, doi:10.1029/2002JD002332, 2002. 16130

Greenblatt, J. B., Jost, H.-J., Loewenstein, M., Podolske, J. R., Bui, T. P., Hurst, D. F., Elkins, J. W., Herman, R. L., Webster, C. R., Schauffler, S. M., Atlas, E. L., Newman, P. A., Lait, L. R., Müller, M., Engel, A., and Schmidt, U.: Defining the polar vortex edge from an $\mathrm{N}_{2} \mathrm{O}$ : potential temperature correlation, J. Geophys. Res., 107, 8268, doi:10.1029/2001JD000575, 2002. 16126, 16130, 16131, 16132, 16133, 16146, 16147

Ivanova, E. V., Volk, C. M., Klein, H., Riediger, O., Strunk, M., Schmidt, U., Ravegnani, F., Ulanovsky, A., and Redaelli, G.: Incomplete Ozon Loss and Weak Mixing in the outer Antarctic Vortex derived from airborne in situ Observations, Geophys. Res. Abstr., 8, 09930, 2006. 16144

Ivanova, E. V.: Evaluation of Transport and Ozone Loss in the Antarctic Polar Vortex by using the Tracer-Based Coordinates, PhD thesis, Johann Wolfgang Goethe Universität, Frankfurt 30 am Main, 2007. 16129, 16144

Labitzke, K.: Die Stratosphäre, Springer Verlag, Berlin, 47-67, 1999. 16125

Lee, A. M., Roscoe, H. K., Jones, A. E., Haynes, P. H., Shuckburgh, E. F., Morrey, M. W., and Pumphrey, H. C.: The impact of the mixing properties within the Antarctic stratospheric

\section{A quasi-Lagrangian coordinate system based on tracer observations}

E. V. Ivanova et al.

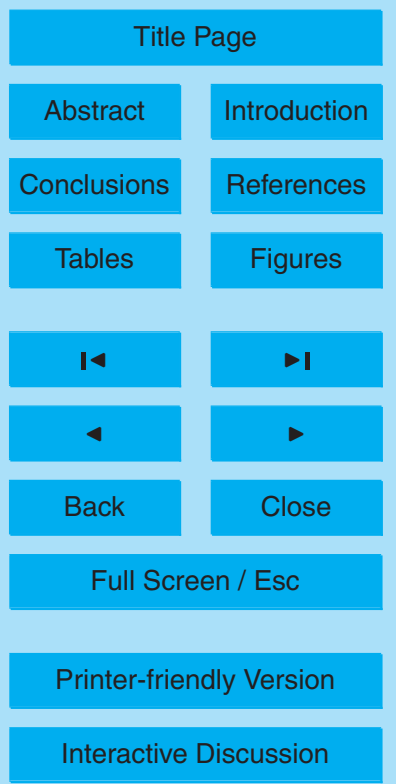


vortex on ozone loss in spring, J. Geophys. Res., 106, 3203-3211, 2001. 16125, 16144, 16147

Lemmen, C., Müller, R., Konopka, P., and Dameris, M.: Critique of the tracer-tracer correlation technique and its potential to analyze polar ozone loss in chemistry-climate models, J.

$5 \quad$ Geophys. Res., 111, 18307, doi: 10.1029/2006JD007298, 2006. 16139

Mahlman, J. D., Levy, H., and Moxim, W. J.: Three-dimensional simulations of stratospheric $\mathrm{N}_{2} \mathrm{O}$ : predictions for other trace constituents, J. Geophys. Res., 91, 2687-2707, 1986. 16138

Michelsen, H. A., Manney, G. L., Gunson, M. R., and Zander, R.: Correlations of stratospheric abundances of $\mathrm{NO}_{\mathrm{y}}, \mathrm{O}_{3}, \mathrm{~N}_{2} \mathrm{O}$, and $\mathrm{CH}_{4}$ derived from ATMOS measurements, J. Geophys.

10 Res., 103, 28347-28359, 1998. 16125, 16139

Möbius, T:: Untersuchungen zu Unterschieden in Tracer-Tracer Korrelationen innerhalb und außerhalb des arktischen Polarwirbels, Diplomarbeit, Johann Wolfgang Goethe Universität, Frankfurt am Main, 2005. 16139

Morgenstern, O., Pyle, J. A., Iwi, A. M., Norton, W. A., Elkins, J. W., Hurst, D. F., and Romashkin,

15 P. A.: Diagnosis of mixing between middle latitudes and the polar vortex from tracer-tracer correlations, J. Geophys. Res., 107, 4321, doi:10.1029/2001JD001224, 2002. 16139

Morgenstern, O. and Pyle, J. A.: Strategies for measuring canonical tracer relationships in the stratosphere, Atmos. Chem. Phys., 3, 259-266, 2003,

http://www.atmos-chem-phys.net/3/259/2003/. 16139

20 Müller, R., Tilmes, S., Konopka, P., Grooß, J.-U., and Jost, H.-J.: Impact of mixing and chemical change on ozone-tracer relations in the polar vortex, Atmos. Chem. Phys., 5, 3139-3151, 2005, http://www.atmos-chem-phys.net/5/3139/2005/. 16125, 16126, 16129, 16130, 16141

Nash, E. R., Newman, P. A., Rosenfield, J. E., and Schoeberl, M. R.: An objective determination of the polar vortex using Ertel's potential vorticity, J. Geophys. Res., 101, 9471-9478, 1996. 16130,16157

Plumb, R. A. and Ko, M. K. W.: Interrelationships between mixing ratios of long-lived stratospheric constituents, J. Geophys. Res., 97, 10145-10 156, 1992. 16131, 16137, 16138

Plumb, R. A., Waugh, D. W., and Chipperfield, M. P.: The effects of mixing on tracer relationships in the polar vortices, J. Geophys. Res., 105, 10047-10 062, 2000. 16138, 16139, $30 \quad 16140$

Plumb, R. A.: Stratospheric Transport, J. Meteorol. Soc. Jpn., 80, 793-809, 2002. 16131, 16140

Plumb, R. A., Heres, W., Neu, J. L., Mahowald, N. M., del Corral, J., Toon, G. C., Ray, E.,

\section{A quasi-Lagrangian coordinate system based on tracer observations}

E. V. Ivanova et al.

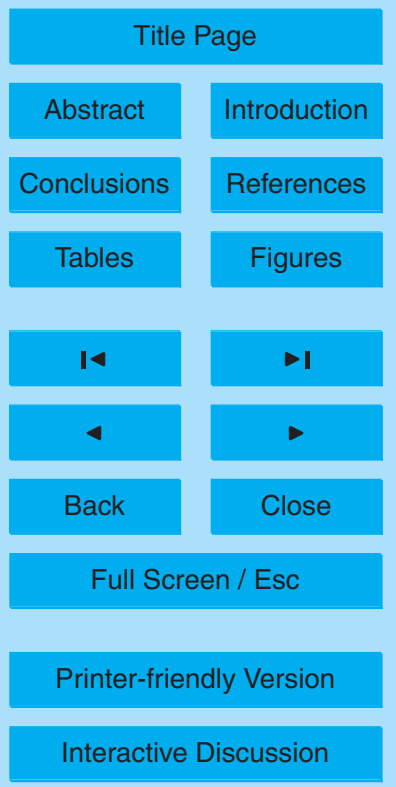


Moore, F., and Andrews, A. E.: Global tracer modeling during SOLVE: High-latitude descent and mixing, J. Geophys. Res., 108, 8308, doi:10.1029/2001JD001023, 2003. 16138, 16139

Plumb, R. A.: Tracer interrelationships in the stratosphere, Rev. Geophys., 45, RG4005, doi:10.1029/2005RG000179, 2007. 16125, 16138, 16139, 16140, 16142, 16147

5 Proffitt, M. H., Kelley, K. K., Powell, J. A., Gary, B. L., Loewenstein, M., Podolske, J. R., Strahan, S. E., and Chan, K. R.: Evidence for Diabatic Cooling and Poleward Transport Within and Around the 1987 Antarctic Ozone Hole, J. Geophys. Res., 94, 16797-16813, 1989a. 16130

Proffitt, M. H., Fahey, D. W., Kelley, K. K., and Tuck, A. F.: High-latitude ozone loss outside the Antarctic ozone hole, Nature, 342, 233-237, 1989b. 16126, 16130

10 Proffitt, M. H., Steinkamp, M. J., Powell, J. A., McLaughlin, R. J., Mills, O. A., Schmeltekopf, A. L., Thompson, T. L., Tuck, A. F., Tyler, T., Winkler, R. H., and Chan, K. R.: In situ ozone measurements within the 1987 Antarctic ozone hole from a high-altitude ER-2 aircraft, J. Geophys. Res., 94, 16547-16555, 1989c. 16130

Proffitt, M. H., Solomon, S., and Loewenstein, M.: Comparison of 2-D model simulations of ozone and nitrous oxide at high latitudes with stratospheric measurements, J. Geophys. Res., 97, 939-944, 1992. 16130

Proffitt, M. H., Aikin, K., Tuck, A. F., Margitan, J. J., Webster, C. R., Toon, G. C., and Elkins, J. W.: Seasonally averaged ozone and nitrous oxide in the Northern Hemisphere lower stratosphere, J. Geophys. Res., 108, 4110, doi:10.1029/2002JD002657, 2003. 16130

20 Randel, W.: Ideas flow on Antarctic vortex, Nature, 364, 105-106, 1993. 16125

Ray, E. A., Moore, F. L., Elkins, J. W., Hurst, D. F., Romashkin, P. A., Dutton, G. S., and Fahey, D. W.: Descent and mixing in the 1999-2000 northern polar vortex inferred from in situ tracer measurements, J. Geophys. Res., 107, 8285, doi:10.1029/2001JD000961, 2002. 16136, 16139, 16141, 16166

Riediger, O.: Entwicklung und Einsatz eines flugzeuggetragenen Instrumentes zur in-situMessung langlebiger Spurengase in der Stratosphäre, PhD thesis, Johann Wolfgang Goethe Universität, Frankfurt am Main, 2000. 16128, 16129, 16135, 16165

Roscoe, H. K., Shanklin, J. D., and Colwell, S. R.: Has the Antarctic Vortex Split before 2002?, J. Atmos. Sci., 62, 3, doi:10.1175/JAS-3331.1, 2005. 16125

30 Rosenfield, J. E., Newman, P. A., and Schoeberl, M. R.: Computations of diabatic descent in the stratospheric polar vortex, J. Geophys. Res., 99, 16677-16 689, 1994. 16136, 16137

Russell, J. M., Gordley, L. L., Park, J. H., Drayson, S. R., Hesketh, W. D., Cicerone, R. J., Tuck, A. F., Frederick, J. E., Harries, J. E., and Crutzen, P. J.: The halogen occultation experiment,

\section{A quasi-Lagrangian coordinate system based on tracer observations}

E. V. Ivanova et al.

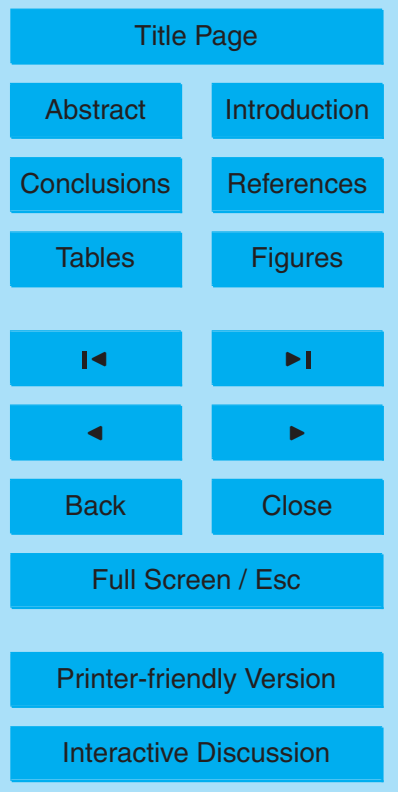


J. Geophys. Res., 98, 10777-10797, 1993.

Sasano, Y., Nakajima, H., Kanzawa, H., Suzuki, M., Yokota, T., Nakane, H., Gernandt, H., Schmidt, A., Herber, A., Yushkov, V., Dorokhov, V., and Deshler, T.: Validation of ILAS Version 3.0 ozone with ozonesonde measurements, Geophys. Res. Lett., 26, 831-834, 1999. 16129, 16161

Schmidt, U., Kulessa, G., Klein, E., Rth, E.-P., Fabian, P., and Borchers, R.: Intercomparison of balloon-borne cryogenic whole air samplers during the MAP/GLOBUS 1983 campaign, Planet. Space Sci., 35, 647-656, 1987. 16139, 16167

Schmidt, U., Bauer, R., Khedim, A., Klein, E., Kulessa, G., and Schiller, C.: Profile observation of long-lived trace gases in the Arctic vortex, Geophys. Res. Lett., 18, 767-770, 1991. 16136

Schoeberl, M. R. and Hartmann, D. L.: The dynamics of the stratospheric Polar Vortex and its relation to springtime ozone depletions, Science, 251, 46-52, 1991. 16125, 16130

Schoeberl, M. R., Lait, L. R., Newman, P. A., and Rosenfield, J. E.: The Structure of the Polar Vortex, J. Geophys. Res., 97, 7859-7882, 1992. 16130

Sitnikov, N. M., Yushkov, V. A., Afchine, A. A., Korshunov, L. I., Astakhov, V. I., Ulanovskii, A. E., Kraemer, M., Mangold, A., Shiller, C., and Ravegnani, F.: The FLASH instrument for water vapour measurements on board the high-altitude airplane, Instr. Exper. Tech., 50, 113-121, 2007. 16129, 16143, 16170

Strahan, S. E., Loewenstein, M., Podolske, J. R., Starr, W. L., Chan, K. R., Proffitt, M. H., and Kelly, K. K.: Correlation of $\mathrm{N}_{2} \mathrm{O}$ and ozone in the Southern polar vortex during the airborne Antarctic ozone experiment, J. Geophys. Res., 94, 16 749-16 756, 1989. 16130, 16134

Strahan, S. E. and Mahlman, J. D.: Evaluation of the SKYHI general circulation model using aircraft $\mathrm{N}_{2} \mathrm{O}$ measurements. 1. Polar winter stratospheric meteorology and tracer morphology, J. Geophys. Res., 99, 10305-10318, 1994.

Strahan, S. E., Nielsen, J. E., and Cerniglia, M. C.: Long-lived tracer transport in the Antarctic stratosphere, J. Geophys. Res., 101, 26615-26 629, 1996.

Strahan, S. E., Loewenstein, M., and Podolske, J. R.: Climatology and small-scale structure of lower stratospheric $\mathrm{N}_{2} \mathrm{O}$ based on in situ observations, J. Geophys. Res., 104, 2195-2208, 1999. 16126

30 Strunk, M.: An Experimental Study on the Mean Age of Stratospheric Air, PhD thesis, Johann Wolfgang Goethe Universität, Frankfurt am Main, 1999. 16128

Tian, W. and Chipperfield, M. P.: Stratospheric water vapor trends in a coupled chemistryclimate model, Geophys. Res. Lett., 33, L06819, doi:10.1029/2005GL024675, 2006. 16143

\section{A quasi-Lagrangian coordinate system based on tracer observations}

E. V. Ivanova et al.

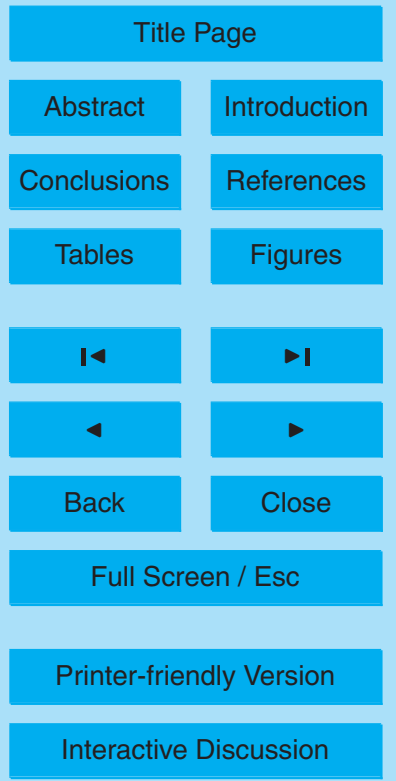


Tilmes, S., Müller, R., Grooß, J.-U., Spang, R., Sugita, T., Nakajima, H., and Sasano, Y.: Chemical ozon loss and related processes in the Antarctic winter 2003 based on Improved Limb Atmospheric Spectrometer (ILAS)-II observations, J. Geophys. Res., 111, D11S12, doi:10.1029/2005JD006260, 2006. 16125, 16129

5 Tuck, A. F., Kelly, K. K., Webster, C. R., Loewenstein, M., Stimpfle, R. M., Proffitt, M. H., and Chan, R. K.: Airborne Chemistry and Dynamics at the Edge of the 1994 Antarctic Vortex, J. Chem. Soc. Faraday Trans., 91, 3063-3071, 1995. 16125, 16130

Tuck, A. F., Brune, W. H., and Hipskind, R. S.: Airborne Southern Hemisphere Ozone Experiment/Measurements for Assessing the Effects of Stratospheric Aircraft (ASHOE/MAESA): A road map, J. Geophys. Res., 102, 3901-3904, 1997.

Ulanovskii, A. E., Luk'yanov, A. N., Yushkov, V. A., Sitnikov, N. M., Volk, M., Ivanova, E. V., and Ravegnani, F.: Estimation of the chemical loss of ozone in the Antarctic stratosphere in the 1999 winter-spring season from direct measurements and simulations, Izv. Atmos. Ocean. Phys., 40, 695-703, 2004. 16145

Volk, C. M., Elkins, J. W., Fahey, D. W., Dutton, G. S., Gilligan, J. M., Loewenstein, M., Podolske, J. R., Chan, K. R., and Gunson, M. R.: Evaluation of source gas lifetimes from stratospheric observations, J. Geophys. Res., 102, 25 543-25564, 1997. 16141, 16169

Vömel, H., Oltmans, S. J., Hofmann, D. J., Deshler, T., and Rosen, J. M.: The evolution of the dehydration in the Antarctic stratospheric vortex, J. Geophys. Res., 100, 13919-13926, $20 \quad$ 1995. 16144

Waugh, D. W., Plumb, R. A., Elkins, J. W., Fahey, D. W., Boering, K. A., Dutton, G. S., Volk, C. M., Keim, E., Gao, R.-S., Daube, B. C., Wofsy, S. C., Loewenstein, M., Podolske, J. R., Chan, K. R., Proffitt, M. H., Kelly, K. K., Newman, P. A., and Lait, L. R.: Mixing of polar vortex air into middle lalitudes as revealed by tracer-tracer scatterplots, J. Geophys. Res., 102, 13119-13134, 1997. 16130, 16139, 16140, 16141, 16169

Werner, A. S.: Quantifying transport into the lowermost stratosphere, PhD thesis, Johann Wolfgang Goethe Universität, Frankfurt am Main, 2006. 16158

WMO: World Meteorological Organization: Global Ozone Research and Monitoring Project - Report No.47, Scientific Assessment of Ozone Depletion: 2002, Chapter 3., Geneva, Switzerland, 2003. 16125

WMO: World Meteorological Organization, Global Ozone Research and Monitoring Project - Report No.50, Scientific Assessment of Ozone Depletion, 2006, Chapter4., Geneva, Switzerland, 2007. 16125

\section{A quasi-Lagrangian coordinate system based on tracer observations}

E. V. Ivanova et al.

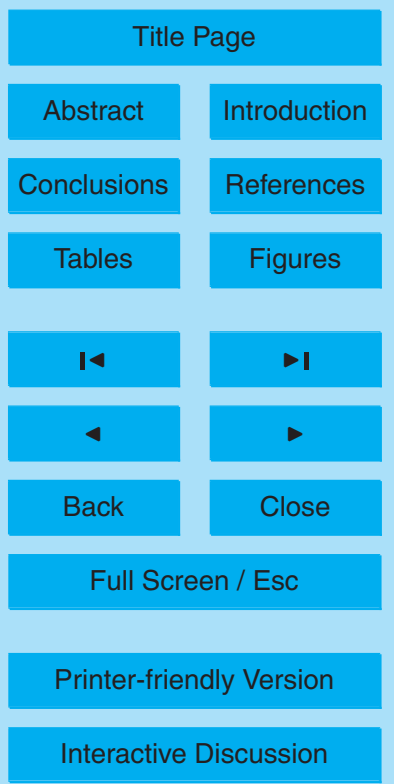


Yushkov, V. A., Ulanovskii, A. E., Lechenuk, N., Roudakov, I., Arshinov, K., Tikhonov, F., Stefanutti, L., Ravegnani, F., Bonafé, U., and Georgiadis, T.: A Chemiluminescent Analyzer for Stratospheric Measurements of the Ozone Concentration (FOZAN), J. Atmos. Oceanic Tech., 16, 1345-1350, 1999. 16129, 16164

5 Yushkov, V. A., Sitnikov, N. M., Ulanovskii, A. E., Ravegnani, F., and Redaelli, G.: Measurements of the ozone and water vapor contents in the stratospheric Antarctic cyclone from the high-altitude M55 Geophysica Aircraft, Izv. Atmos. Ocean. Phys., 37, 275-280, 2001. 16145

\section{ACPD}

8, 16123-16173, 2008

\section{A quasi-Lagrangian coordinate system based on tracer observations}

E. V. Ivanova et al.

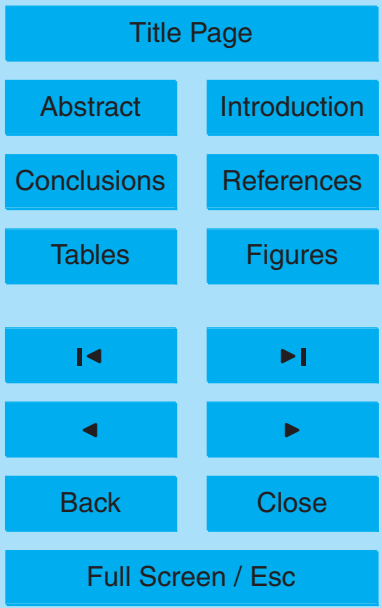

Printer-friendly Version

Interactive Discussion 


\section{ACPD}

8, 16123-16173, 2008

\section{A quasi-Lagrangian coordinate system based on tracer observations}

Table 1. The difference between positions of the inner polar vortex evaluated with the $\delta \chi$ and Nash criteria. The values of the potential temperature $\Theta$ refer to the altitudes where the aircraft M55 Geophysica crossed the inner Antarctic vortex in four research flights of the APA-GAIA campaign.

\begin{tabular}{ccccccc}
\hline & Flight & Flight & Flight & Flight & Flight & Flight \\
& 990921 & 990921 & 990923 & 991002 & 991002 & 991012 \\
\hline$\Theta(\mathrm{K})$ & 380 & 440 & 420 & 410 & 420 & 360 \\
Difference $(\mathrm{km})$ & 33 & 45 & 231 & 794 & 112 & 21 \\
\hline
\end{tabular}

E. V. Ivanova et al.

Title Page

Abstract

Conclusions

Tables

Figures

14

4

Back

Full Screen / Esc

Printer-friendly Version

Interactive Discussion 


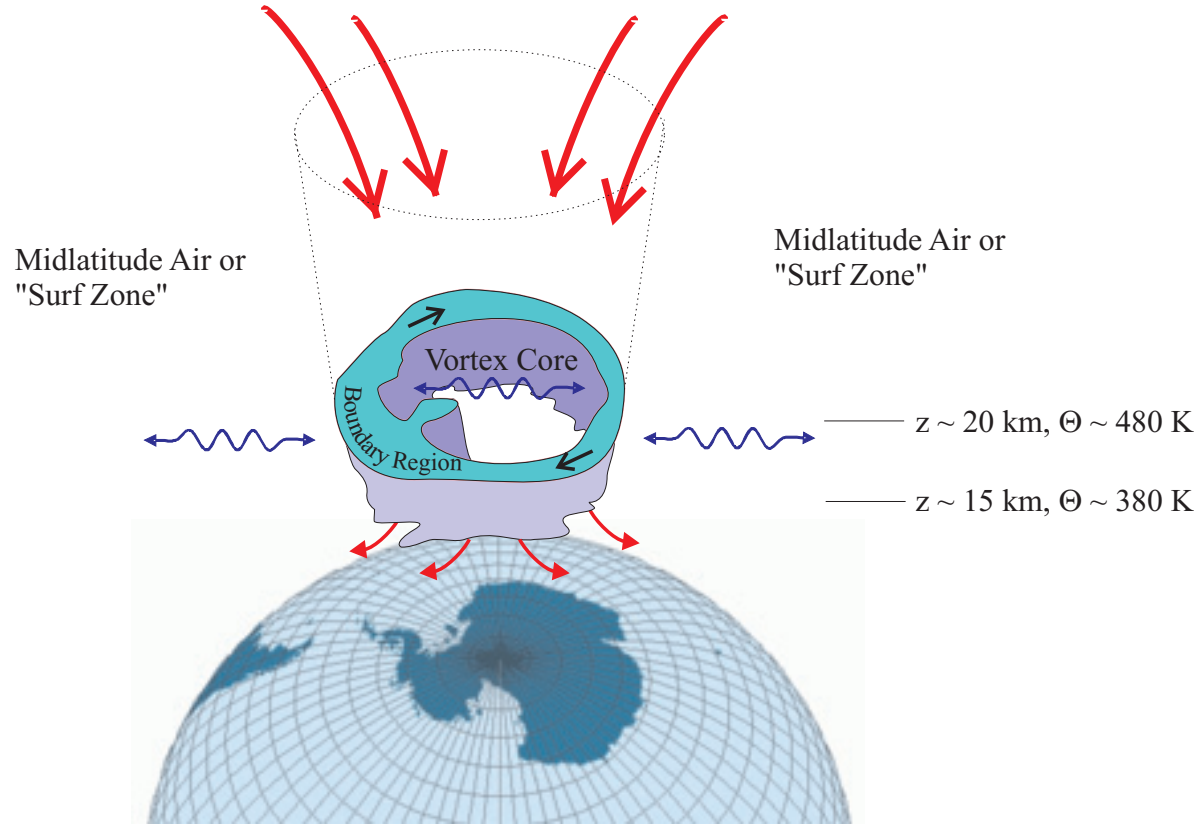

Fig. 1. Schematic picture of the Antarctic polar vortex, based on the meteorological data for 1 June 1999 by using the Nash criterion (Nash et al., 1996). The green-coloured ring-shaped area shows cross section of the vortex boundary region at $480 \mathrm{~K}$. The direction of the BrewerDobson circulation is shown by the red arrows, and the blue arrows refer to mixing along isentropic surfaces. Note that the vertical coordinate (altitude $z$ ) scales the latitude-longitude coordinates as about 1:100.

\section{A quasi-Lagrangian coordinate system based on tracer observations}

E. V. Ivanova et al.

\section{Title Page}

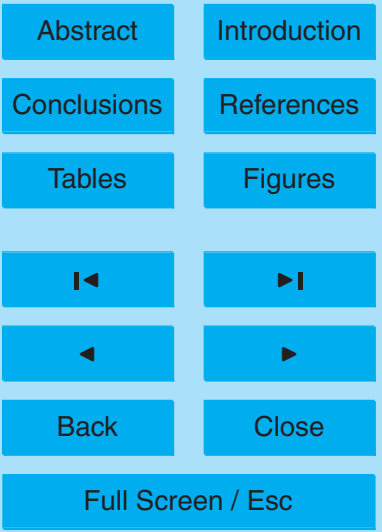

Printer-friendly Version

Interactive Discussion 


\section{ACPD}

8, 16123-16173, 2008

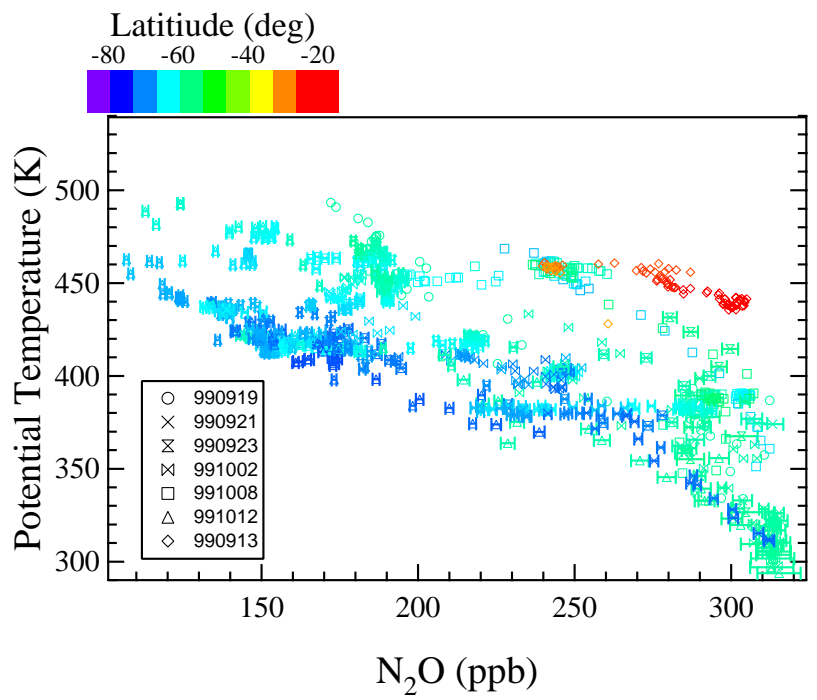

A quasi-Lagrangian coordinate system based on tracer observations

E. V. Ivanova et al.

Title Page

Abstract

Introduction

Conclusions

References

Tables

Figures

14

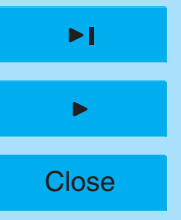

Back

Full Screen / Esc

Printer-friendly Version

Interactive Discussion 


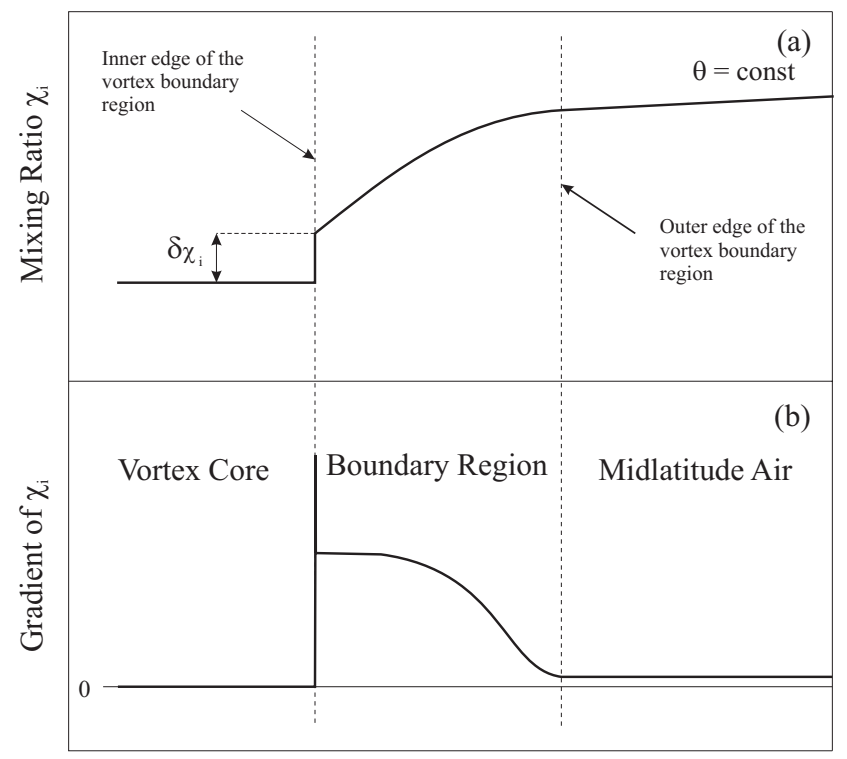

Latitudinal Coordinate

\section{ACPD}

8, 16123-16173, 2008

\section{A quasi-Lagrangian coordinate system based on tracer observations}

E. V. Ivanova et al.

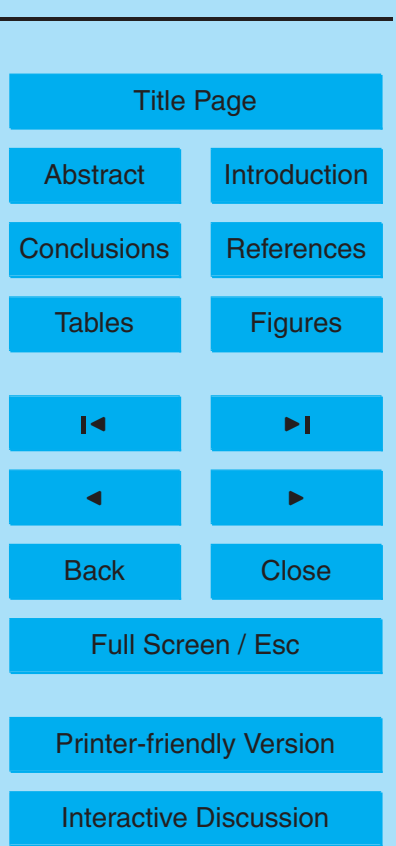
Fig. 3. Schematic of the $\delta \chi$-criterion for finding the inner vortex edge. (a) The $\left.\chi_{i}\right|_{\Theta=\text { const }}$
distribution across the vortex boundary region. (b) The horizontal (isentropic) gradient of the mixing ratio $\chi_{i}$ across the vortex boundary region. The function $\nabla \chi_{i}$ is nearly zero in the vortex core and surf zone areas and has a well-developed positive spike at the position of a $\delta_{\chi_{i}}$-step in the $\chi_{i}$ distribution, i.e. at the inner vortex edge. The measured values of $\chi_{i}$ are attributed to the vortex core if $\left.\Delta \chi_{i}\right|_{\Theta=\text { const }} \leq\left.\delta_{\chi_{i}}\right|_{\Theta=\text { const }}$ and to the vortex boundary region or midlatitude air if $\left.\Delta \chi_{i}\right|_{\Theta=\text { const }}>\left.\delta_{\chi_{i}}\right|_{\Theta=\text { const }}$. 

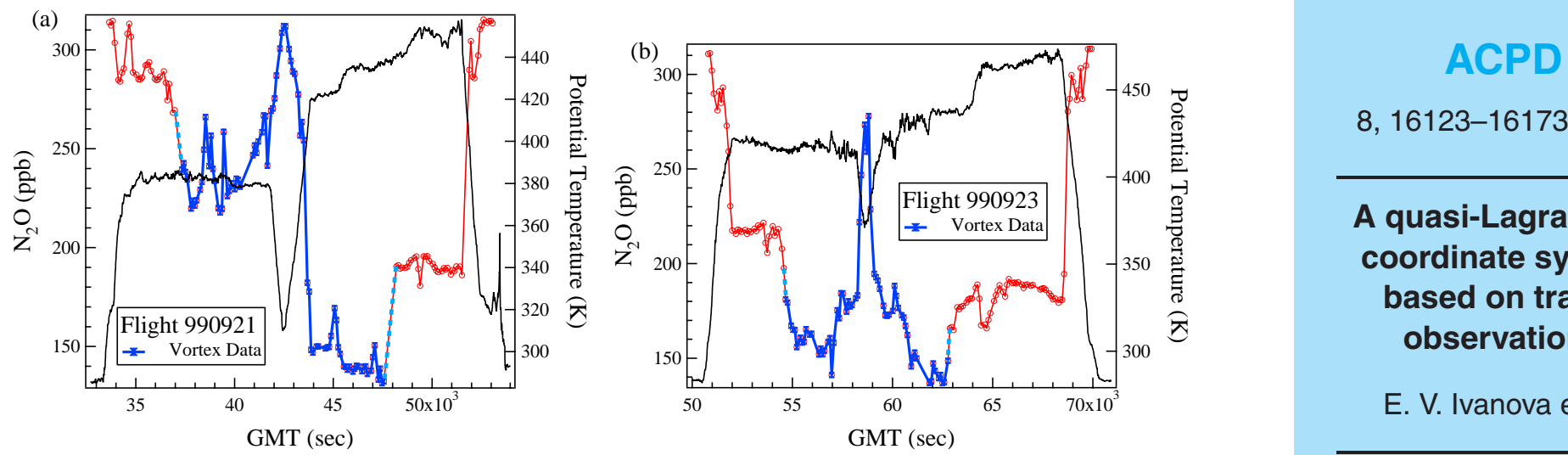

8, 16123-16173, 2008

\section{A quasi-Lagrangian coordinate system based on tracer observations}

E. V. Ivanova et al.
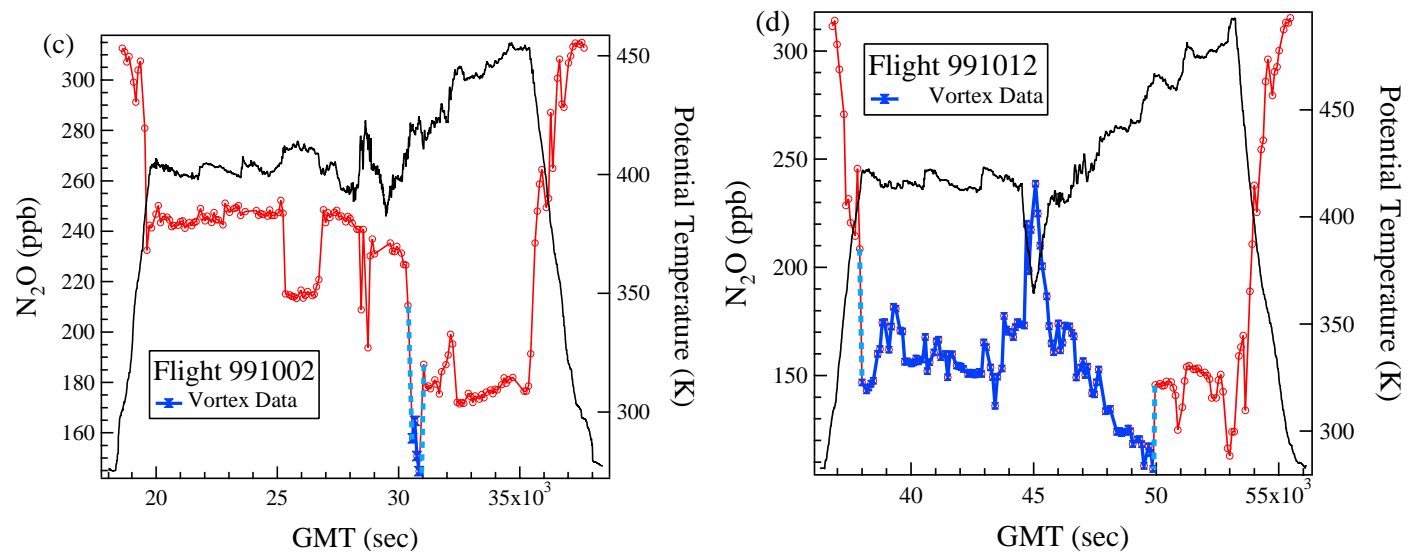

Title Page

Abstract

Introduction

Conclusions

References

Tables

Figures

14

$\rightarrow$

$<$

Back

Close

Full Screen / Esc

Fig. 4. The $\mathrm{N}_{2} \mathrm{O}$ mixing ratio distribution (red and blue lines) measured with HAGAR in the Southern Hemisphere during the APE-GAIA campaign on (a) 21st of September 1999, (b) 23rd of September 1999, (c) 2nd of October 1999 and (d) 12th of October 1999. The blue curves refer to the Antarctic vortex core, and the light-blue bold dotted segments indicate the $\delta \chi_{\mathrm{N}_{2} \mathrm{O}}$-steps. The black lines show the potential temperature profile along the flight routes. A dive-climb maneuver done in the middle of the flight can clearly be identified in (a), (b) and (d). 


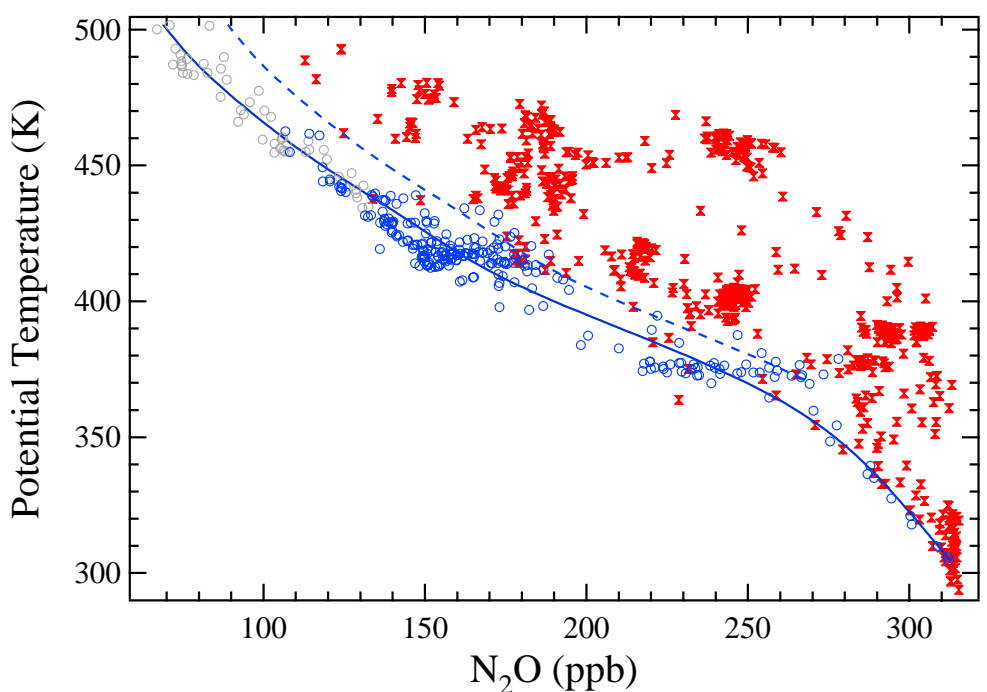

Fig. 5. The $\mathrm{N}_{2} \mathrm{O}$ mixing ratio $\chi_{\mathrm{N}_{2} \mathrm{O}}$ against the potential temperature $\Theta$ for five research flights of the APE-GAIA campaign. The measured points are coloured in accordance with Fig. 4: the blue and grey circles refer to the vortex core, while the red crosses belong either to the vortex boundary region or to the surf zone. The vortex reference profile $\chi_{\mathrm{N}_{2} \mathrm{O}}^{\text {vort }}=\chi_{\mathrm{N}_{2} \mathrm{O}}^{\text {vort }}(\Theta)$ (the blue solid line) is inferred as a least-square fitting curve of the data recorded within the vortex core. Note that for $\Theta \geq 463 \mathrm{~K}$ the reference profile is found by using the satellite data of ILAS-II (Sasano et al., 1999), see the grey circles. The inner vortex edge defined as $\chi_{\mathrm{N}_{2} \mathrm{O}}=\chi_{\mathrm{N}_{2} \mathrm{O}}^{\mathrm{vort}}+\delta_{\chi_{\mathrm{N}_{2} \mathrm{O}}}$ with $\delta_{\chi_{\mathrm{N}_{2} \mathrm{O}}}=20 \mathrm{ppb}$ is shown by the blue dashed line.

\section{A quasi-Lagrangian coordinate system based on tracer observations}

E. V. Ivanova et al.

\section{Title Page}

\section{Abstract}

Conclusions

\section{Tables}

14

$\triangleleft$

Back
Introduction

References

Figures

$\rightarrow$

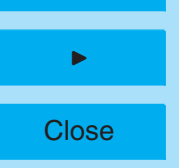

Full Screen / Esc

Printer-friendly Version 


\section{ACPD}
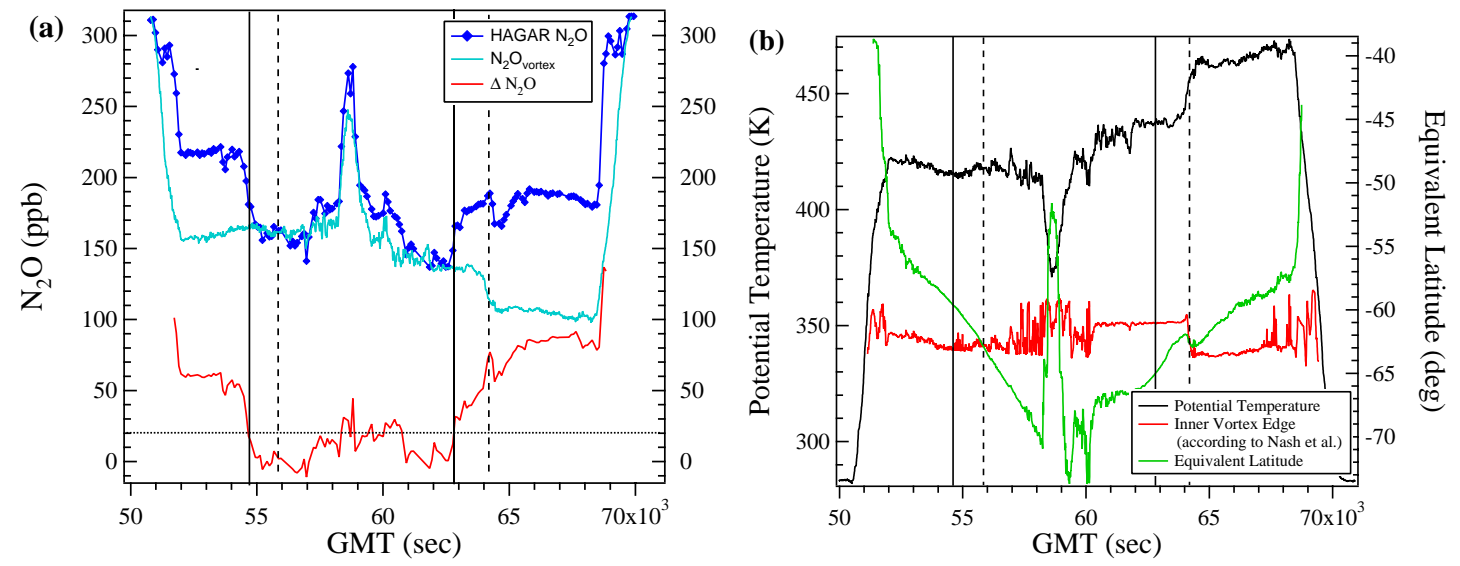

\section{A quasi-Lagrangian coordinate system based on tracer observations}

E. V. Ivanova et al.

Fig. 6. Comparison of the Nash criterion, Eq. (2), and the $\Delta \chi$-criterion for finding the inner vortex edge. The research flight on 23 September of the APE-GAIA campaign. The vertical solid (dashed) lines show the inner vortex edge determined with the $\Delta \chi$ (Nash) criterion. (a) The dark blue line - the measured mixing ratio $\chi_{\mathrm{N}_{2} \mathrm{O}}$ along the flight (see also Fig. $4 \mathrm{~b}$ ), the light blue line - the vortex reference mixing ratio $\chi_{\mathrm{N}_{2} \mathrm{O}}^{\text {vort }}(\Theta)$, and the red line $-\Delta \chi_{\mathrm{N}_{2} \mathrm{O}}=\chi_{\mathrm{N}_{2} \mathrm{O}}-\chi_{\mathrm{N}_{2} \mathrm{O}}^{\text {vort }}$. (b) The black (green) line shows the potential temperature $\Theta$ (equivalent latitude $\varphi_{\mathrm{e}}$ ) along the flight. The red line indicates the position of the inner vortex edge calculated with the Nash criterion for the relevant values of $\Theta$.

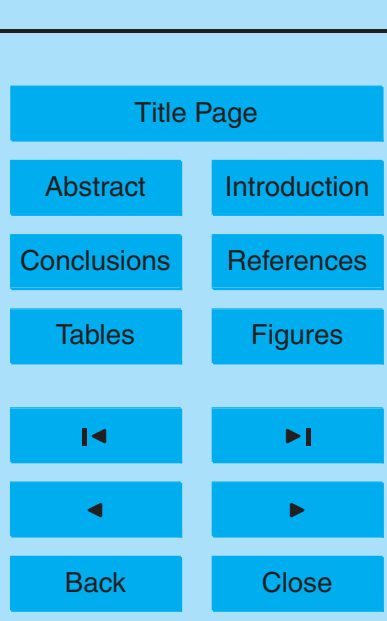

Full Screen / Esc

Printer-friendly Version 


\section{ACPD}

8, 16123-16173, 2008

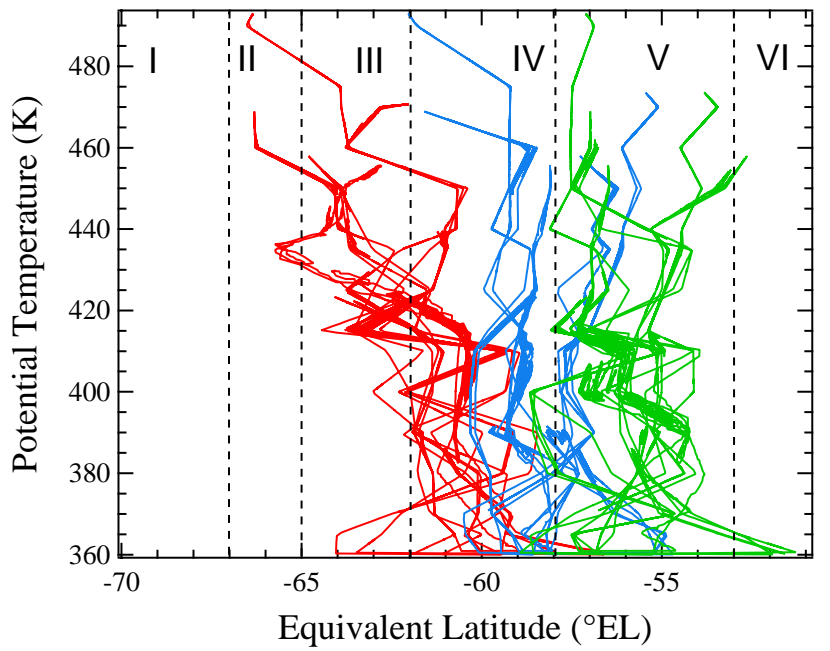

Fig. 7. The vortex edge (blue curves), the inner vortex edge (red curves) and the outer vortex edge (green curves) calculated with the Nash criterion, Eqs. (1-2), for the research flights of the APE-GAIA campaign. The equivalent latitude bins used in the analysis of the measurements (see Fig. 8a) are indicated by the vertical dashed lines and labelled I-VI.

\section{A quasi-Lagrangian coordinate system based on tracer observations}

E. V. Ivanova et al.

\section{Title Page}

\section{Abstract}

Conclusions

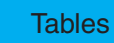

14

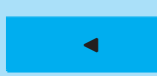

Back
Introduction

References

Figures

$\rightarrow$

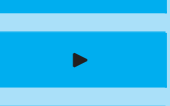

\section{Full Screen / Esc}

Printer-friendly Version

Interactive Discussion 


\section{ACPD}
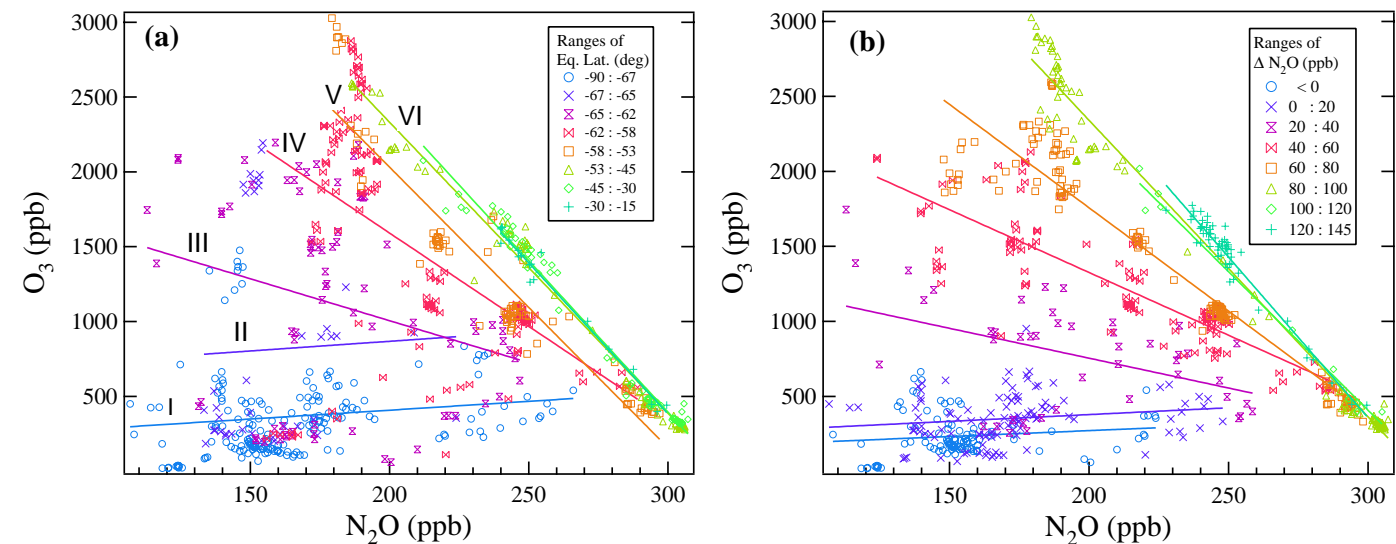

\section{A quasi-Lagrangian coordinate system based on tracer observations}

E. V. Ivanova et al.

Fig. 8. The $\mathrm{O}_{3}: \mathrm{N}_{2} \mathrm{O}$ distribution measured in five research flights of the APE-GAIA campaign (the ozone mixing ratio $\chi_{\mathrm{O}_{3}}(\Theta)$ recorded by the FOZAN instrument Yushkov et al., 1999). (a) The data points are coloured, binned into eight groups and linearly fitted according to the equivalent latitude $\varphi_{\mathrm{e}}$. The first six $\varphi_{\mathrm{e}}$-bins, I-VI, are the same as those plotted in Fig. 7. (b) The data points are coloured according to their $\Delta \chi_{\mathrm{N}_{2} \mathrm{O}}$. A bin selection of the points into eight groups with $\left[\Delta \chi_{\mathrm{N}_{2} \mathrm{O}}\right]_{\mathrm{bin}}=20 \mathrm{ppb}$ is used. The straight lines show linear fits for each bin. In (a) and (b) only the data points with $\Theta \geq 380 \mathrm{~K}$ are shown.

Title Page

Abstract

Introduction

Conclusions

References

Tables

Figures

14

Back

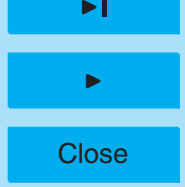

Full Screen / Esc

Printer-friendly Version

Interactive Discussion 


\section{ACPD}

8, 16123-16173, 2008

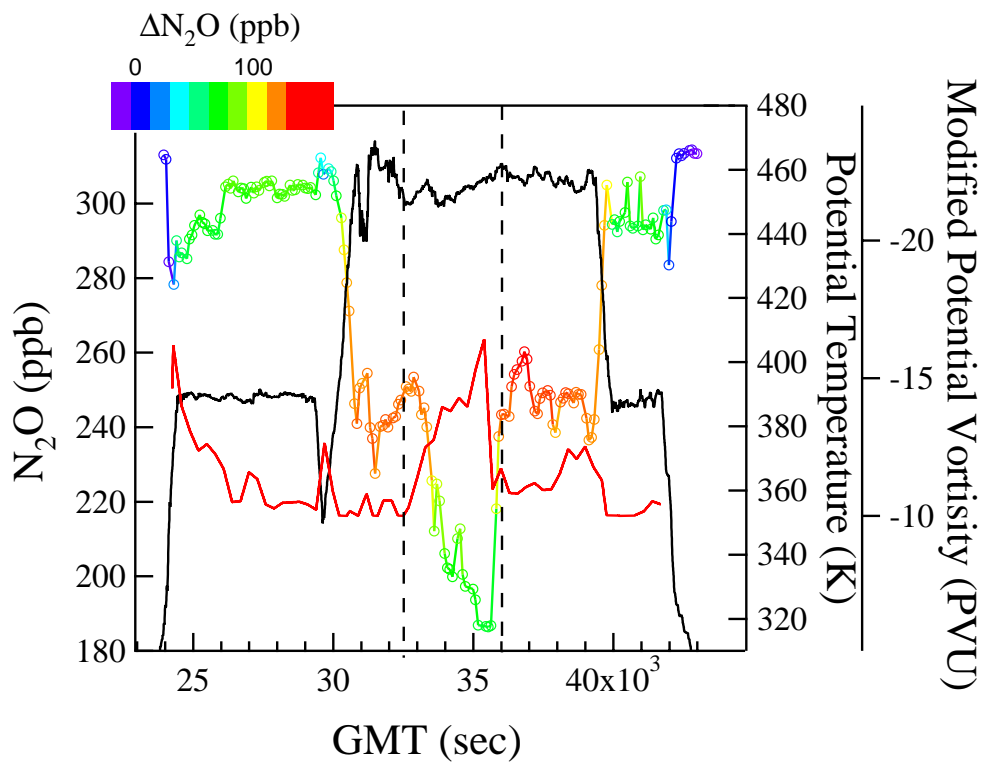

A quasi-Lagrangian coordinate system based on tracer observations

E. V. Ivanova et al.

Title Page

Abstract

Conclusions

Tables

14

4

Back
Introduction

References

Figures

I

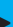

Close The vertical dashed lines indicate the filament area which is determined by using the modified potential vorticity shown by the red curve $\left(\Pi_{\varepsilon} \simeq-10 \mathrm{PVU}\right.$ in midlatitude air against $\Pi_{\varepsilon}^{\text {fil }} \simeq$ -16 PVU in the filament Riediger, 2000).

\section{Full Screen / Esc}

Printer-friendly Version

Interactive Discussion 


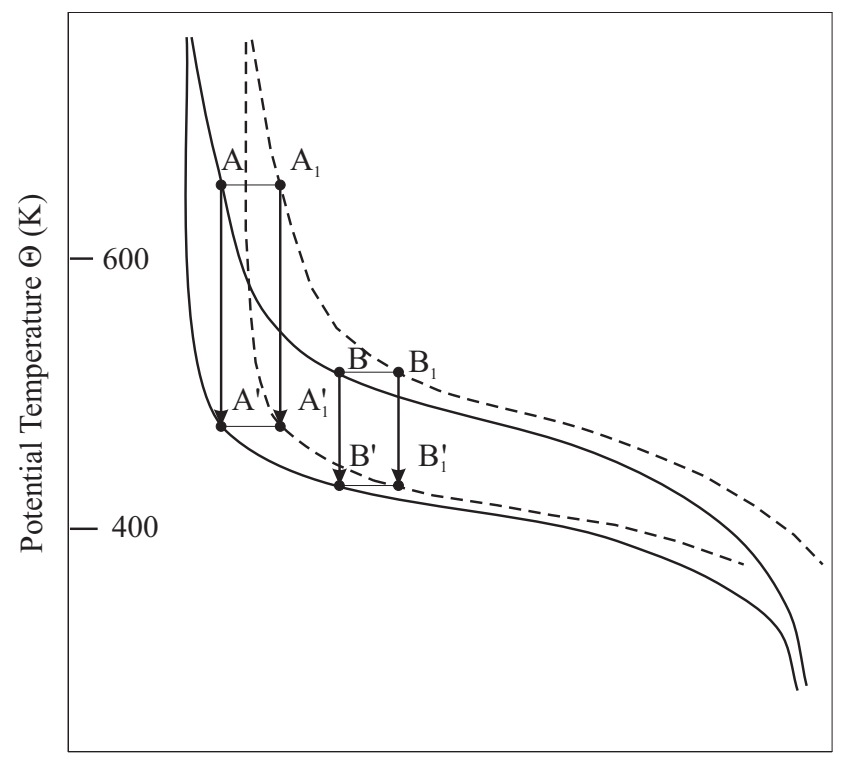

\section{ACPD}

8, 16123-16173, 2008

\section{A quasi-Lagrangian coordinate system based on tracer observations}

E. V. Ivanova et al.

Mixing Ratio $\chi_{\mathrm{N}_{2} \mathrm{O}}(\mathrm{ppb})$

Fig. 10. Schematic of the diabatic descent of the $\mathrm{N}_{2} \mathrm{O}$ tracer in the polar stratosphere during winter months. Two solid and two dashed curves illustrate the diabatic descent that occurs within the same time interval $\Delta T$ at two different meridional coordinates. The $\Theta$-inhomogeneous subsidence of an air-parcel is shown by the vertical arrows $\left(A A^{\prime}>B B^{\prime}\right.$ and $\left.A_{1} A_{1}^{\prime}>B_{1} B_{1}^{\prime}\right)$. The plot qualitatively scales the data points balloon-collected in the Arctic vortex area during the end 1999 - beginning 2000 (Ray et al., 2002).

Title Page

\section{Abstract}

Introduction

Conclusions

References

Tables

Figures

14

4

Back

\section{Full Screen / Esc}

Printer-friendly Version

Interactive Discussion 

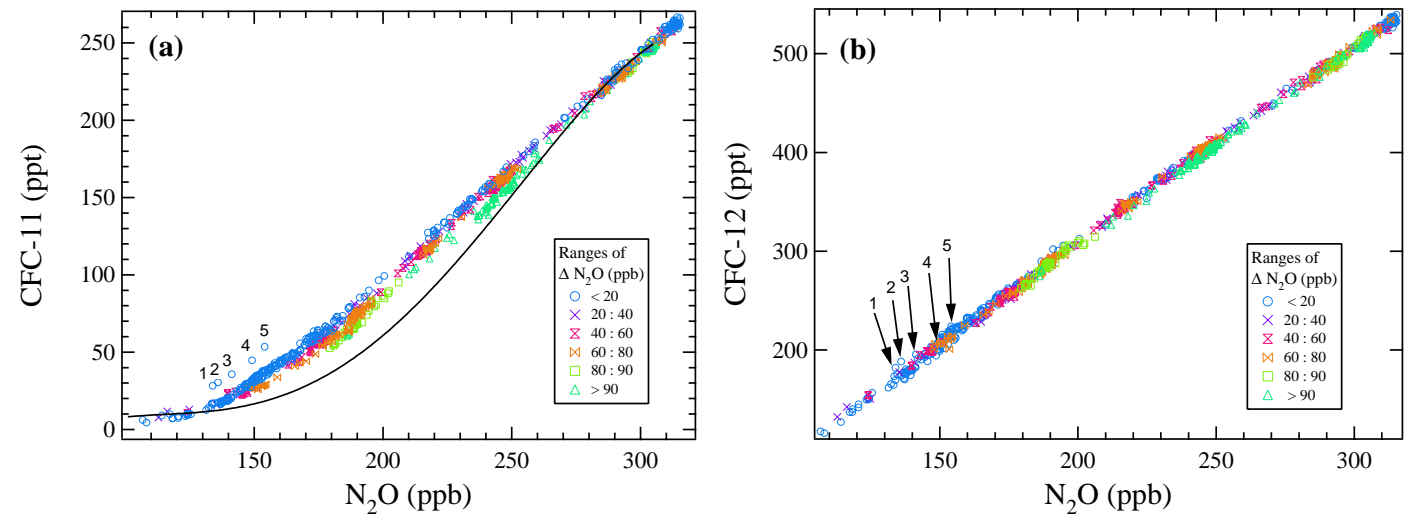

\section{ACPD}

8, 16123-16173, 2008
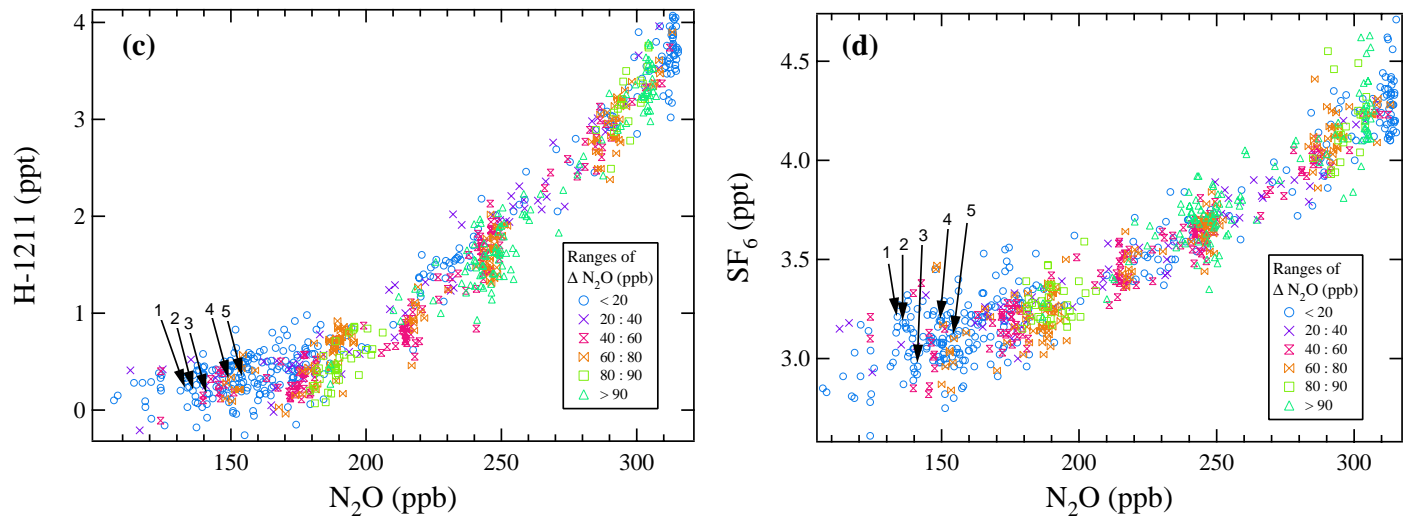

Fig. 11. The tracer-tracer relationships: (a) CFC-11: $\mathrm{N}_{2} \mathrm{O}$, (b) CFC-12: $\mathrm{N}_{2} \mathrm{O}$, (c) $\mathrm{H} 1211: \mathrm{N}_{2} \mathrm{O}$ and (d) $\mathrm{SF}_{6}: \mathrm{N}_{2} \mathrm{O}$, inferred from the measurements done in the APE-GAIA campaign. The points are binned and coloured according to $\left[\Delta \chi_{\mathrm{N}_{2} \mathrm{O}}\right]_{\text {bin }}=20 \mathrm{ppb}$. The black curve in (a) shows the midlatitude reference correlation CFC-11: $\mathrm{N}_{2} \mathrm{O}$ calculated by using balloon measurements (Schmidt et al., 1987; Engel et al., 1997). The marked points 1-5 and the midlatitude reference curve are discussed in the text.

A quasi-Lagrangian coordinate system based on tracer observations

E. V. Ivanova et al.

\section{Title Page}

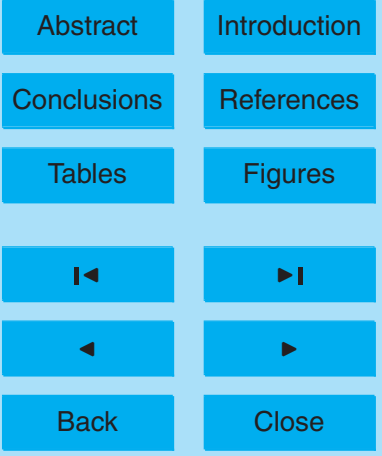

Full Screen / Esc

Printer-friendly Version

Interactive Discussion 


\section{ACPD}

8, 16123-16173, 2008

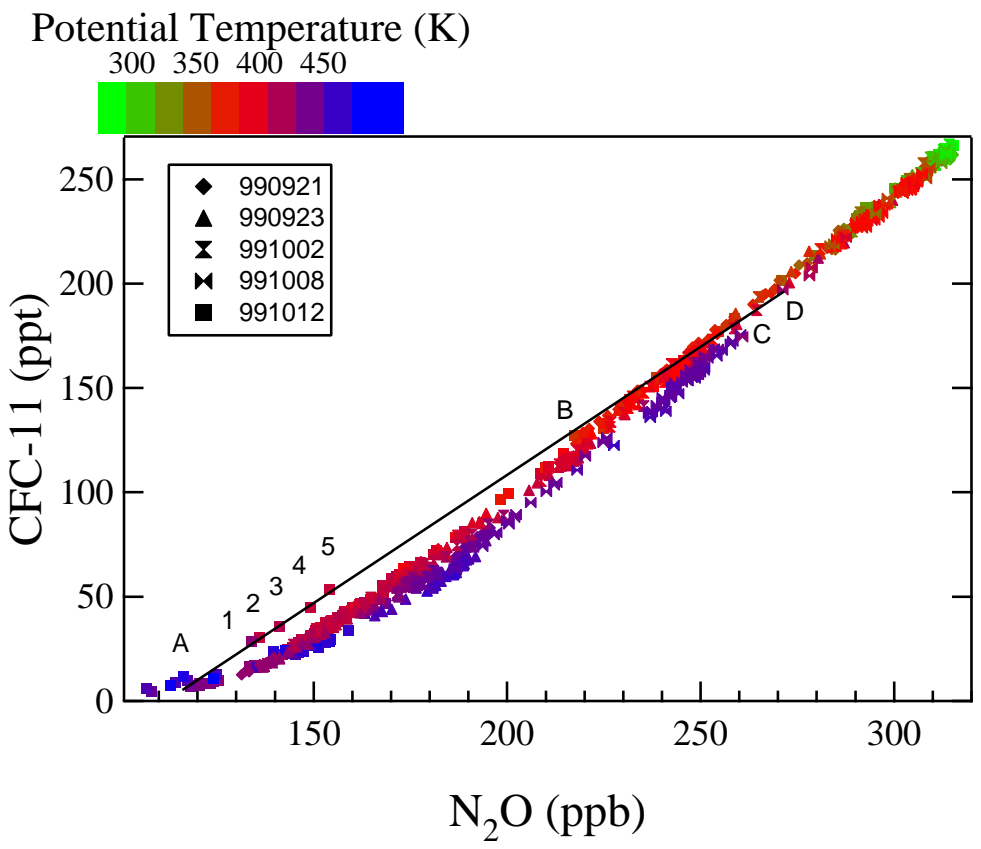

\section{A quasi-Lagrangian coordinate system based on tracer observations}

E. V. Ivanova et al.

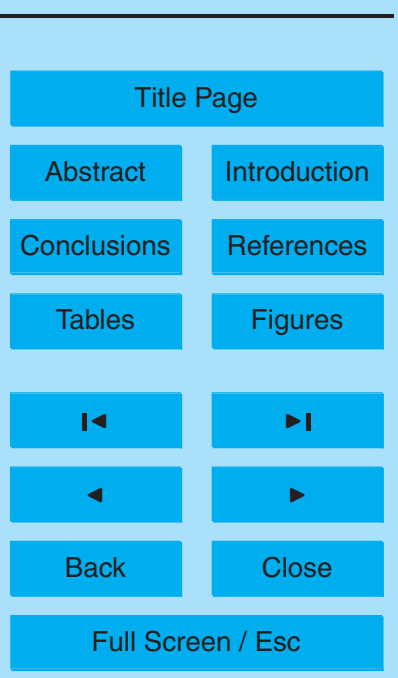

Fig. 12. The CFC-11: $\mathrm{N}_{2} \mathrm{O}$ relationship measured for the Antarctic polar vortex region during the APA-GAIA campaign. The parametrization in terms of the potential temperature $\Theta$ is used. The straight line through the anomalous points $1-5$ is explained in the text.

Printer-friendly Version

Interactive Discussion 


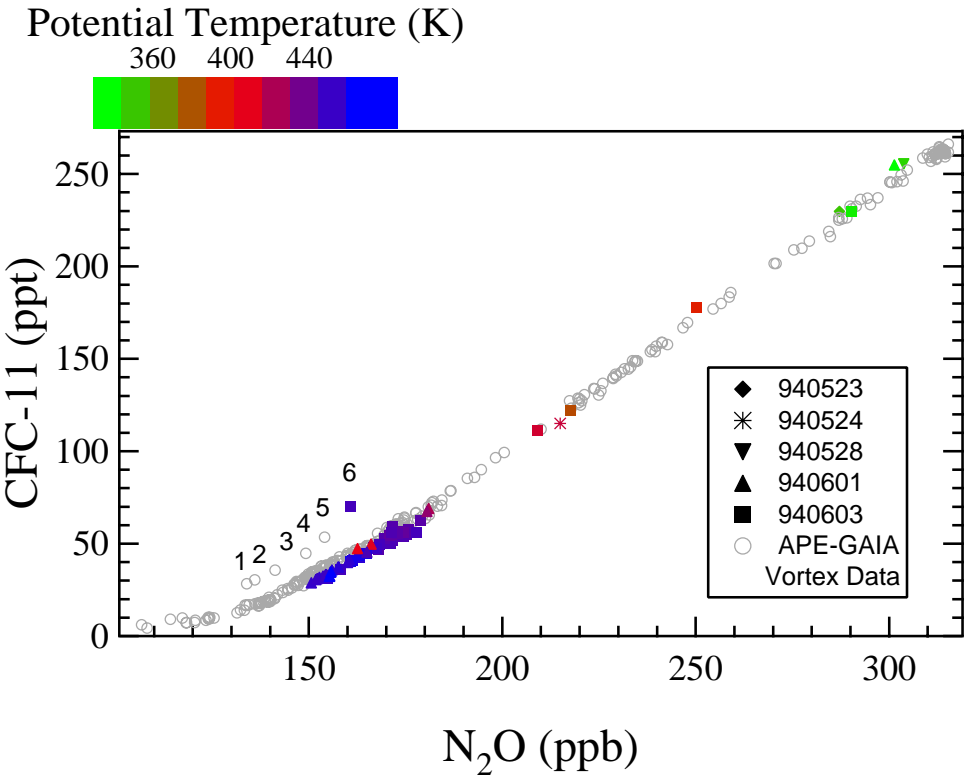

Fig. 13. The tracer-tracer relationship CFC-11: $\mathrm{N}_{2} \mathrm{O}$ for the Antarctic vortex core in the $\Theta$ parametrization (coloured points), inferred from the measurements of the ASHOE campaign (Waugh et al., 1997; Volk et al., 1997). For comparison, the grey markers show the data-points of the APE-GAIA campaign (see blue open circles in Fig. 11a). The anomalous point 6 of the ASHOE measurements is consistent with and supplements the ensemble of anomalous points 1-5 recorded in the research flight 12 October of the APE-GAIA campaign.
$8,16123-16173,2008$

\section{A quasi-Lagrangian coordinate system based on tracer observations}

E. V. Ivanova et al.

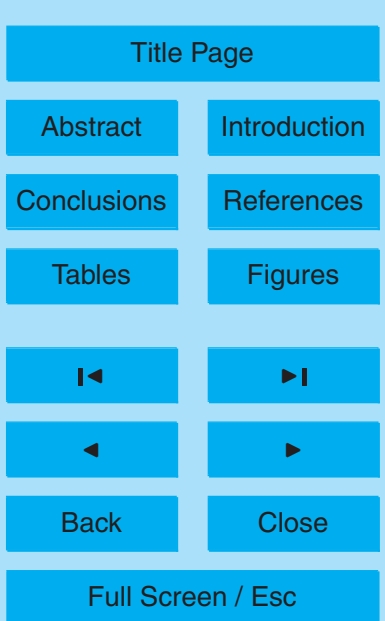

Printer-friendly Version

Interactive Discussion 


\section{ACPD}

8, 16123-16173, 2008

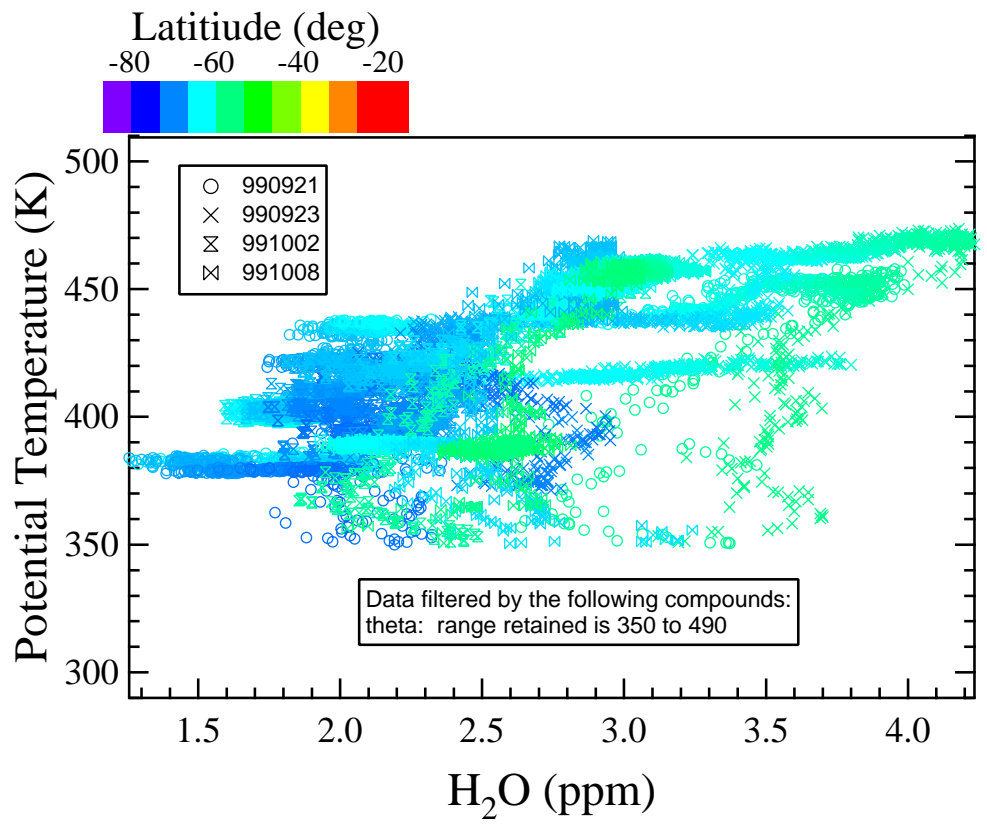

A quasi-Lagrangian coordinate system based on tracer observations

E. V. Ivanova et al.

\section{Title Page}

Abstract

Conclusions

Tables

14

4

Back

Full Screen / Esc

Printer-friendly Version

Interactive Discussion 


\section{ACPD}

8, 16123-16173, 2008

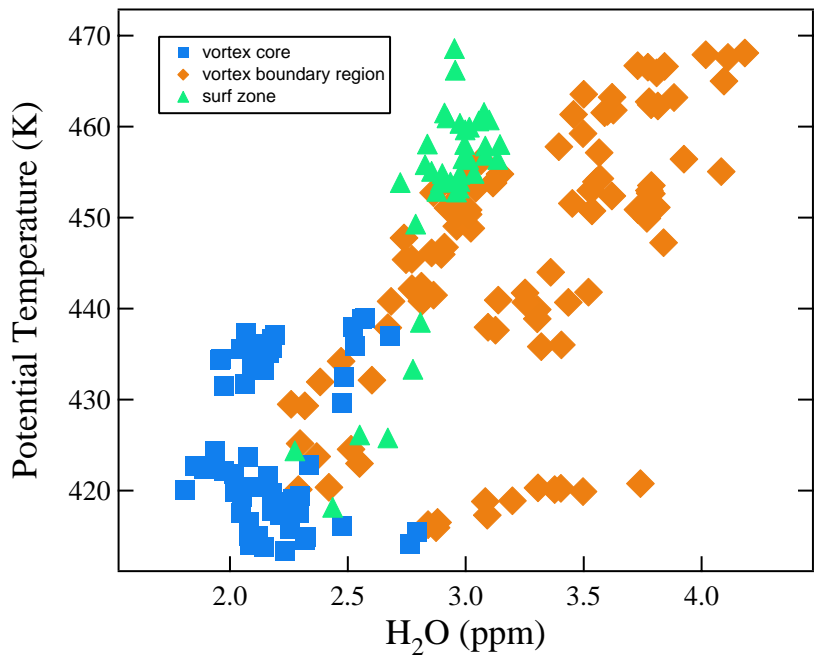

A quasi-Lagrangian coordinate system based on tracer observations

E. V. Ivanova et al.

Fig. 15. The mixing ratio $\chi_{\mathrm{H}_{2} \mathrm{O}}$ against the potential temperature $\Theta$. The $\Delta \chi_{\mathrm{N}_{2} \mathrm{O}}$ parametrization is used: $\Delta \chi_{\mathrm{N}_{2} \mathrm{O}} \leq 20 \mathrm{ppb}$ (blue square markers) refers to the polar vortex core, $20 \mathrm{ppb} \leq$ $\Delta \chi_{\mathrm{N}_{2} \mathrm{O}} \leq 90 \mathrm{ppb}$ (brown diamond markers) - to the vortex boundary region, and $90 \mathrm{ppb} \leq \Delta \chi_{\mathrm{N}_{2} \mathrm{O}}$ (green triangular markers) - to the midlatitude surf zone. The data points are recorded in the research flights on 21 and 23 September, and on 2 and 8 October of the APE-GAIA campaign.

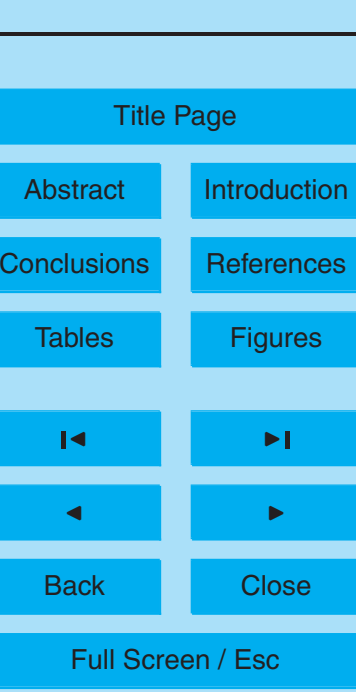

Printer-friendly Version

Interactive Discussion 


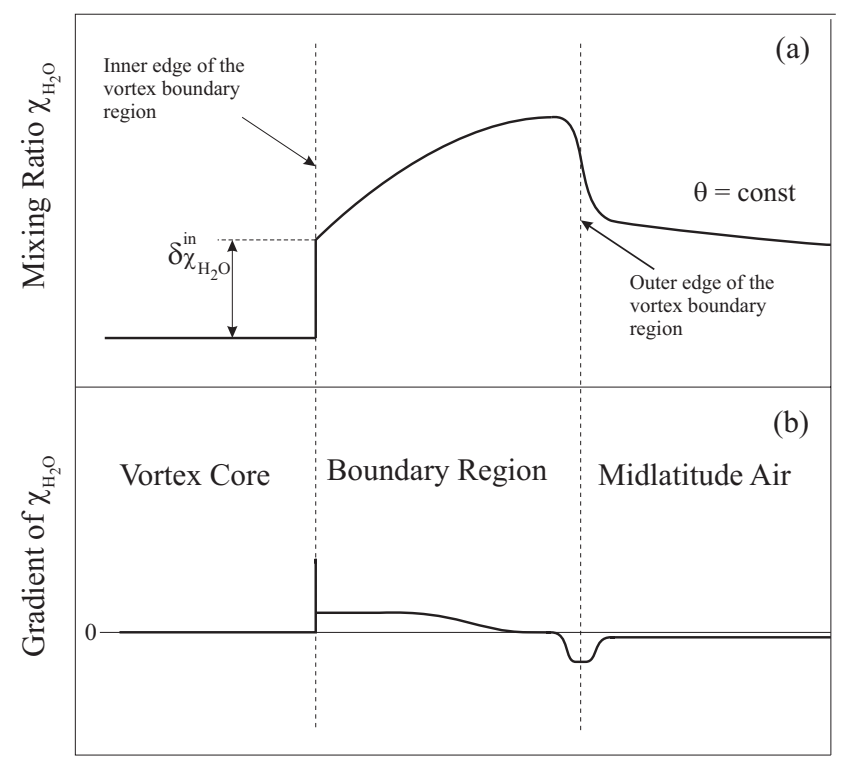

Latitudinal Coordinate $\mathrm{x}$

Fig. 16. Schematic of the $\delta \chi$-criterion for finding the inner and outer vortex edges by using the water vapor as a tracer. (a) The $\left.\chi_{\mathrm{H}_{2} \mathrm{O}}\right|_{\Theta=\text { const }}$ distribution across the vortex boundary region. (b) The horizontal (isentropic) gradient of the mixing ratio $\chi_{\mathrm{H}_{2} \mathrm{O}}$ across the vortex boundary region. The function $\nabla \chi_{\mathrm{H}_{2} \mathrm{O}}$ is nearly zero in the vortex core and surf zone areas and has a well-developed positive spike at the position of a $\delta_{\chi_{\mathrm{H}_{2} \mathrm{O}}}^{\text {in }}$-step in the $\chi_{\mathrm{H}_{2} \mathrm{O}}$ profile, i.e. at the inner vortex edge. The position of the outer vortex edge is defined as minimum gradient of $\chi_{\mathrm{H}_{2} \mathrm{O}}$.

\section{ACPD}

8, 16123-16173, 2008

\section{A quasi-Lagrangian coordinate system based on tracer observations}

E. V. Ivanova et al.

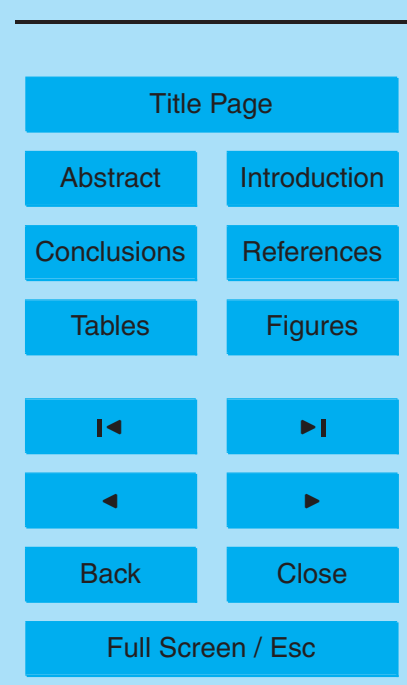

Printer-friendly Version

Interactive Discussion 


\section{ACPD}
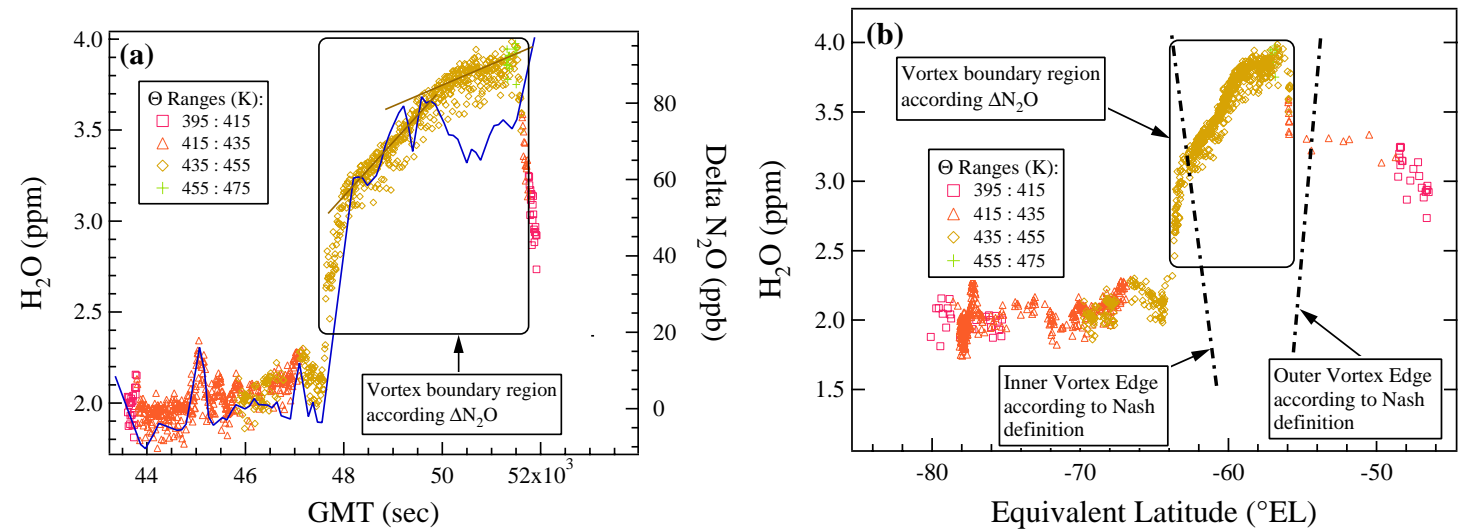

\section{A quasi-Lagrangian coordinate system based on tracer observations}

E. V. Ivanova et al.

Fig. 17. The $\mathrm{H}_{2} \mathrm{O}$ mixing ratio, $\chi_{\mathrm{H}_{2} \mathrm{O}}$, measured in the research flight on 21 September of the APE-GAIA campaign (see also Fig. 4a). The coloured markers refer to $\chi_{\mathrm{H}_{2} \mathrm{O}}$, the blue solid line shows the $\Delta \chi_{\mathrm{N}_{2} \mathrm{O}}$ meridional coordinate, and the dash-dotted solid lines indicate the inner and outer vortex edges evaluated with the Nash criterion, Eq. (2). The potential temperature $\Theta$ ranges according to the colour, as specified in the insets. (a) The mixing ratio $\chi_{\mathrm{H}_{2} \mathrm{O}}$ against the flight time, and (b) $\chi_{\mathrm{H}_{2} \mathrm{O}}$ against the equivalent latitude $\varphi_{\mathrm{e}}$.

Title Page

Abstract

Introduction

Conclusions

References

Tables

Figures

14

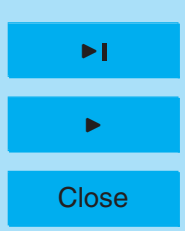

Back

Full Screen / Esc

Printer-friendly Version

Interactive Discussion 